\title{
Closed-loop supply chains under reward-penalty mechanism: retailer collection and asymmetric information ${ }^{11}$
}

\author{
Wenbin Wanga, Yu Zhanga, Yuanyuan Li ${ }^{\mathrm{a}}$, Xuejuan Zhao ${ }^{\mathrm{a}}$, \\ Mingbao Cheng ${ }^{\text {b* }}$ \\ ${ }^{\mathrm{a}}$ School of Management, China University of Mining and Technology, Xuzhou, Jiangsu \\ 221116, PR. China \\ ${ }^{b^{*}}$ School of Management, Guangdong University of Technology, Guangzhou, Guangdong \\ 510520,PR. China, email:chengmb99@hotmail.com
}

\begin{abstract}
Being motivated by the issue of waste electrical and electronic equipment (WEEE) collection, we consider a contract design problem for a manufacturer with entrusting the collection of WEEE to a retailer. However, the manufacturer has asymmetric information on the collection effort level of the retailer. This paper designs an information screening contract for the manufacturer to obtain the information of collection effort level, and the optimal decision-making with several properties of contract parameters are derived. The results indicate that the manufacturer would offer lower wholesale price and higher buy-back price for the H-type retailer while charge more franchise fee to the H-type retailer. Considering the government intervention, reward-penalty mechanism (RPM) is developed to stimulate the asymmetric information closedloop supply chain (CLSC). We also analyze the impacts of RPM by comparing the cases whether or not RPM is implemented. The comparison results show that the RPM can lower the wholesale price and retail price meanwhile raise buy-back price and collection quantity. Finally, several numerical studies are conducted for more managerial insights.
\end{abstract}

Keywords: Information screening contract; Closed-Loop Supply Chain (CLSC); Reward-Penalty Mechanism (RPM); Waste Electrical and Electronic Equipment (WEEE)

\section{Introduction}

The rapidly updating and shortening life cycles of products have led to industries seemingly producing new electric and electronic products almost daily, which can account for the increase in growth of waste electrical and electronic equipment(WEEE). It is estimated that, by 2017, the WEEE of the whole world will reach about 65 million tons which will increase by 33 percent compared with 49 million tons in 2012. There are more than 700 chemical materials in WEEE,

1 *Corresponding author: Mingbao Cheng, School of Management, Guangdong University of Technology, Guangzhou, 510520 PR China, E-mail: chengmb99@hotmail.com. 
and half of them are hazardous to human health, while WEEE may derive 80-1500 $\mathrm{g}$ of gold and 350-1850 g of silver per ton, valued at several thousand US dollars.( http://www.tijinw.com/)

Instead of incineration and landfill, the used products should be taken into collecting, refurbishing and remanufacturing (Thierry et al., 1995). Remanufacturing, as a significant part of closed-loop supply chain (CLSC), is the process of taking the used product to an as-good-as-new condition by repairing, replacing and restoring its components as necessary (Aras et al., 2011). Remanufacturing has both economic and environmental benefits (Huysman et al, 2015. Wang et al, 2015). From the economic point of view, remanufacturing is lucrative since the cost of remanufacturing is typically $40-60 \%$ of the cost of manufacturing a new product with only $20 \%$ of the effort, and the remanufactured product is of the same quality as a new product sold with the same warranty (Mitra, 2007). Remanufacturing is not only an economic viable solution, but also positively contributing to the environment by conserving resources (Sharma et al, 2016). Meanwhile, the manufacturer in such a CLSC usually faces the risk of asymmetric information, for example, the collection cost parameter of the collector ( $\mathrm{Li}$ et al, 2014) and the collection effort cost of the retailer (Zhang et al, 2014). From another aspect to achieve sustainable development, many governments have taken steps to stimulate the collection of the used products, especially for WEEE. For instance, a number of legislations with respect to product recovery, such as the Paper Recycling Directive, the End-of-Life Vehicle Directive and the WEEE Directive etc, have been implemented in the European Union (Giri and Sharma, 2015). China also has started to carry out the WEEE Recycling Management Regulation and adopt subsidization to the manufacturer to stimulate collection. The governmental financial intervention on CLSC can improve the social welfare and chain-based profits (Sheu and Chen, 2012). Combined with the government intervention, it's a challenging problem for the manufacturer to attain the complete information in the asymmetric information CLSC.

Research on CLSC has gained considerable attention since it arose, and various strategic and operational aspects of CLSC were studied, such as CLSC network designing and planning, production planning and inventory management, etc. Interested reader can refer to Ataus et al (2008), Ilgin and Gupta (2010), Souza (2013) and Govindan et al. (2015) for a comprehensive review. In our paper, literature mainly related to three research streams: contract design problem in CLSC, government intervention and its impact on the CLSC and the collection channel of CLSC.

Contract design is a crucial factor to coordinate and manage the CLSC members. Savaskan et al. (2004) proposed three decentralized models and find retailer-based collection much more effective, then proposed a coordination mechanism if the retailer is incentivized to induce collection. Savaskan and Wassenhove (2006) further extended the above model to multiple setting that the retailing is competitive and showed that the manufacturer should entrust the collection of used products to the retailers under certain conditions. Hammond and Beullens (2007) formulated an equilibrium model for WEEE with variable inequality in a Cournot pricing game. Kaya (2010) 
studied an incentive production model for remanufacturing decisions in a stochastic demand setting. Kenné et al. (2012) addressed a production planning model to minimize the sum of the holding and backlog costs for manufacturing and remanufacturing products in a continuous time stochastic context. Özkır and Başlıgil (2013) proposed a multiple objective optimization model in uncertain environment regarding three recovery options.

Some studies have focused on the collection channel of the CLSC. Thierry et al. (1995) presented products recovery management that the recovery options were classified into repairing, refurbishing, remanufacturing and collecting. Atasu and Wassenhove (2010) extended it to product take-back (collection) issues. Huang et al. (2013) examined optimal strategies of a CLSC with dual collecting channel, in which the retailer and the third party collect WEEEs competitively. Giovanni and Zaccour (2014) studied whether a remanufacturer should manage his own waste collection or outsource it to a collector. He (2015) modeled a closed-loop supply chain (CLSC) with a manufacturer and its supply channels - recycle channel and reliable supply channel.

Since the government act as a significant role in the CLSC, government intervention has also received much more attention from researchers. Atasu and Subramanian (2012) investigated the implications of collective and individual producer responsibility models of product take-back laws for WEEE. Vlachos et al. (2007) tackled the development of efficient capacity planning policies for remanufacturing facilities in reverse supply chains, taking into account the take-back obligation imposed by legislation. Webster and Mitra (2007) proposed a two-period manufacturerremanufacturer competitive model to study the collective versus individual product collection under the take-back laws. Mitra and Webster (2008) examined the influence of government's remanufacturing subsidy on the manufacturer and the remanufacturer based on a two-period manufacturer-remanufacturer competitive model. Georgiadis and Besiou (2008) examined the impact of ecological motivation manifesting through legislation and green image factor. Plambeck and Wang (2009) found that adopting the "fee-upon-disposal" policy will motivate manufacturers to design for recyclability. Aksen et al. (2009) developed models to guide the government to subsidize manufacturers, while Atasu et al. (2009) discussed effective conditions for government to legislate WEEE recycling and remanufacturing policy. Atasu and Wassenhove (2012) proved that it is necessary to enforce collection and recycling of WEEE from the operations perspective. Rahman and Subramanian (2012) found that the government legislation can motivate the computer recycling operations. Govindan et al. (2013) found the CLSC members are not only directed by the value of the WEEEs but also by regulations. Atasu et al. (2013) compared two forms of product take-back legislation with manufacturer-operated and state-operated systems, and Ma et al. (2013) investigated how consumption-subsidy influences dual-channel CLSC.

The aforementioned literature makes an important contribution to the theory development of our research. But, most literatures adopt the government intervention policy and study CLSC under symmetric information environment. In contrast to the above references, this paper investigates the asymmetric information CLSC. In this paper, we consider that in the CLSC the 
manufacturer deputes the collection of WEEE to the retailer. The collection quantity of WEEE relies strictly on the retailer's collection effort level which is the retailer's private information unavailable to the manufacturer. The retailer can choose to be high collection effort level or low collection effort level while the manufacturer only knows the probability of the retailer being $\mathrm{H}$ collection effort level. In the asymmetric information CLSC, we design an information screening contract to screen the retailer's collection effort level and the optimal decision-making and properties of contract parameters are derived. In addition, a reward-penalty mechanism (RPM) for the government to intervene in the asymmetric information CLSC is developed. The RPM prescribes a targeted collection quantity and a reward-penalty intensity. If the collection quantity is more or less than the targeted collection quantity, the manufacturer will receive a reward or a penalty. The impacts of the RPM are studied by comparing the cases with or without the implementation of the RPM.

The remainder of this paper is organized as follows. Section 2 formalizes the problem. Section 3 investigates the decision-making and contract parameters of the asymmetric information CLSC in which the manufacturer designs an information screening contract. Decision-making of the asymmetric information CLSC under RPM is addressed in Section 4, while Section 5 compares the two models and addresses the key findings. A numerical study is given to validate the models and develop managerial insights in Section 6. Section 7 remarks the conclusions and future research.

\section{Problem formulation}

\subsection{Model description}

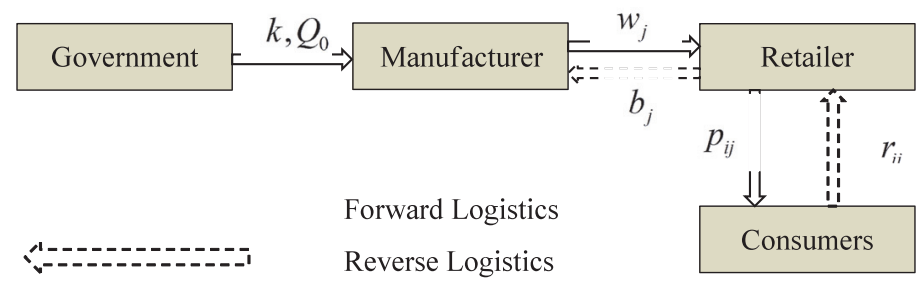

Figure 1. The closed-loop supply chain structure with retailer collection under government's RPM

The closed-loop supply chain structure considered in this paper is shown as Figure 1 which gives the general structure of the CLSC under RPM, and the solid line represents the direction of forward logistics while the dotted line indicates the direction of reverse logistics. The CLSC has one manufacturer, one retailer and the consumer. As the Stackelberg leader, the manufacturer entrusts the collection of WEEE to the retailer. According to assumptions, the retailer chooses high collection effort level or low collection effort level, denoted as H-type retailer or L-type retailer respectively. The retailer obtains WEEE from consumers at the collection price $r_{i j}$ and 
sells them back to the manufacturer at buy-back price $b_{j}$. The manufacturer gives priority to WEEE-recycled materials and components in production due to the lower cost. The manufacturer sells the production at wholesale price $w_{j}$ to the retailer, who then sells the products to final consumers at the retail price $p_{i j}$. For the manufacturer, how to seek the retailer's private information with the information screening contract is as follows: (1) the manufacturer designs a set of contracts according to the probability of being H-type retailer; (2) the retailer decides to accept which contract; (3) the manufacturer identifies the collection effort level of the retailer through the contract choice of the retailer.

\subsection{Notations}

In this paper, the collection effort level of the retailer is divided into high and low level. The parameters with superscript $H$ are related to high collection effort level while parameters with superscript $L$ are referred to low collection effort level. Superscript $*$ indicates the optimal decision results in the scenario. The specific parameters are expressed as follows:

$c_{n}$ : Manufacturer's production cost of using new component;

$c_{r}$ : Manufacturer's production cost of using recycled WEEE's component;

$\Delta$ : Unit saving cost is expressed as $\Delta=c_{n}-c_{r}$, differences of production cost of new materials or recycled components ;

$e_{i}$ : Collection effort level of the retailer, $i \in\{H, L\}, e_{H}$ denotes high collection effort level, $e_{L}$ represents low collection effort level, and $e_{H}>e_{L}$;

$r_{i j}$ : Collection price when the retailer chooses $j$ contract to collect WEEE while her real collection effort level is $i$, where $i, j \in\{H, L\}$;

$b_{j}:$ Buy-back price when the retailer chooses contract $j, j \in\{H, L\}$;

$w_{j}$ : Wholesale price of new product when the retailer chooses contract $j, j \in\{H, L\}$;

$p_{i j}$ : Retail price when the retailer chooses contract $j$ to sell new products while her real collection effort level $i, i \in\{H, L\}, j \in\{H, L\}$;

$T_{r j}$ : Franchise fee paid by the retailer who chooses contract $j$ to the manufacturer under her real collection effort level $i, j \in\{H, L\}$. Franchise fee is a common phenomenon in practice, such as franchised store; 
$v$ : The probability of the retailer being $H$ collection effort level, which is symmetric information.

$Q_{i j}$ : Collection quantity when the retailer choose contract $j$ to collect WEEE under her real collection effort level $i, i \in\{H, L\}, j \in\{H, L\}$;

$E\left(\pi_{m i}\right):$ The expected profit of the manufacturer when the retailer chooses contract $i, i \in\{H, L\} ;$

$E\left(\pi_{r i j}\right):$ The expected profit when the retailer chooses contract junder her collection effort level $i, i \in\{H, L\}, j \in\{H, L\}$;

$\pi_{r}^{0}:$ The reserved profit which is available to the retailer without contract;

$k:$ The reward-penalty intensity established by government;

$Q_{0}$ : The target collection quantity set by government.

\subsection{Basic assumptions}

(i) There are no differences between remanufactured products and new products.

(ii) We assume $\Delta=c_{n}-c_{r}>0$, where unit production cost $c_{n}$ is higher than $c_{r}$. We also assume that the unit cost of remanufactured product is consolidated, i.e. $c_{r}$, which can avoid tedious calculation but won't influence the management insights in the model.

(iii) We assume that the new components take precedence over collected WEEE materials and components in production.

(iv) In this model, the manufacturer and the retailer are risk neutral, without considering risk aversion or risk preference.

(v) The market demand is $D=\phi-p_{i j}+\theta, i, j \in\{H, L\}$, where $\phi$ is the base market size, $p_{i j}$ is the retail price, and $\theta$ is a random variable and satisfies the uniform distribution $U(0, a),(a>0)$, whose probability density function is $f($.$) and probability$ distribution function is $F($.$) .$

(vi) We assume the retailer collection quantity $Q_{i j}$ is a linear function of the collection effort level and the collection price, $Q_{i j}=e_{i}+r_{i j}$. Due to the dependence of collection quantity on the retailer's collection effort level and the collection price, the expression of the collection quantity can be given by the formula above. 


\section{Decision-making of CLSC without the RPM（Case 1)}

In this section, we investigate the information screening contract designed for the manufacturer to attain the private information of the retailer in the CLSC. Figure 1 shows that the reverse buyback and forward wholesale connect the manufacturer with retailer. So the information screening contract can be expressed as $\left\{G_{H}\left(b_{H}, w_{H}, T_{r H}\right), G_{L}\left(b_{L}, w_{L}, T_{r L}\right)\right\}$ composed of the wholesale price $w$, the buy-back price $b$ and franchise fee $T$.

In accordance with the assumptions (v) and (vi), the expected profit of the manufacturer when the retailer chooses contract $G_{H}$ can be expressed as:

$$
\begin{aligned}
E\left(\pi_{m H}\right)= & \int_{0}^{z_{H}}\left(\phi-p_{H H}+x\right)\left(w_{H}-c_{r}\right) f(x) d x+\int_{z_{H}}^{a}\left(\phi-p_{H H}+x\right)\left(w_{H}-c_{n}\right) f(x) d x \\
& +\int_{z_{H}}^{a}\left(e_{H}+r_{H H}\right)\left(c_{n}-c_{r}\right) f(x) d x-b_{H}\left(e_{H}+r_{H H}\right)+T_{r H}
\end{aligned}
$$

In Eq.(1), $z_{H}=e_{H}+r_{H H}-\phi+p_{H H}$, the new remanufactured products can satisfy the market demand if $0<x \leq z_{H}$, if $z_{H}<x<a$, market demand is more than the collection quantity of WEEEs, new remanufactured products and new-manufactured products meet the market demand.

Similarly, when the retailer chooses contract $G_{L}$, the expected profit of manufacturer can be formulated as:

$$
\begin{aligned}
E\left(\pi_{m L}\right)= & \int_{0}^{z_{L}}\left(\phi-p_{L L}+x\right)\left(w_{L}-c_{r}\right) f(x) d x+\int_{z L}^{a}\left(\phi-p_{L L}+x-e_{L}-r_{L L}\right)\left(w_{L}-c_{n}\right) f(x) d x \\
& +\int_{z_{L}}^{a}\left(e_{L}+r_{L L}\right)\left(w_{L}-c_{r}\right) f(x) d x-b_{L}\left(e_{L}+r_{L L}\right)+T_{r L}
\end{aligned}
$$

In Eq. (2), $z_{L}=e_{L}+r_{L L}-\phi+p_{L L}$, if $0<x \leq z_{L}$, the collection quantity of WEEEs is more than the demand of new products, so the new remanufactured products can satisfy market demand. However, if $z_{L}<x<a$, market demand is more than the collection quantity of WEEEs, new remanufactured products and new-manufactured products meet market demand together.

If the retailer exerts $H$ level of collection effort and chooses contract $G_{H}$, her expected profit is:

$$
\begin{aligned}
E\left(\pi_{r H H}\right)= & \left(b_{H}-r_{H H}\right)\left(e_{H}+r_{H H}\right)-e_{H}^{2} / 4 \\
& +\left(p_{H H}-w_{H}\right) \int_{0}^{a}\left(\phi-p_{H H}+x\right) f(x) d x-T_{r H}
\end{aligned}
$$

where $e_{H}^{2} / 4$ is the cost of collection effort.

When the retailer adopts $H$ level of collection effort but chooses contract $G_{L}$, in this case her expected profit is:

$$
\begin{aligned}
E\left(\pi_{r H L}\right)= & \left(b_{L}-r_{H L}\right)\left(e_{H}+r_{H L}\right)-e_{H}^{2} / 4 \\
& +\left(p_{H L}-w_{L}\right) \int_{0}^{a}\left(\phi-p_{H L}+x\right) f(x) d x-T_{r L}
\end{aligned}
$$


If the retailer makes $L$ level of collection effort adopting contract $G_{L}$, the profit of the retailer is given as follows:

$$
\begin{aligned}
E\left(\pi_{r L L}\right)= & \left(b_{L}-r_{L L}\right)\left(e_{L}+r_{L L}\right)-e_{L}^{2} / 4 \\
& +\left(p_{L L}-w_{L}\right) \int_{0}^{a}\left(\phi-p_{L L}+x\right) f(x) d x-T_{r L}
\end{aligned}
$$

Where $e_{L}^{2} / 4$ denotes the cost of collection effort.

As the retailer exerts $L$ level of collection effort but chooses the contract $G_{H}$, the expected profit of the retailer is denoted as:

$$
\begin{aligned}
E\left(\pi_{r L H}\right)= & \left(b_{H}-r_{L H}\right)\left(e_{L}+r_{L H}\right)-e_{L}^{2} / 4 \\
& +\left(p_{L H}-w_{H}\right) \int_{0}^{a}\left(\phi-p_{L H}+x\right) f(x) d x-T_{r H}
\end{aligned}
$$

In the CLSC under random demand environment without the government intervention, the retailer's collection effort level information is asymmetric. The manufacturer seeks to maximize the expected profit which can be expressed as:

$$
\begin{array}{ll}
\max & E\left(\pi_{m}\right)=v E\left(\pi_{m H}\right)+(1-v) E\left(\pi_{m L}\right) \\
\text { s.t. } & \left(p_{H H}^{*}, r_{H H}^{*}\right)=\arg \max E\left(\pi_{r H H}\right) \\
& \left(p_{L L}^{*}, r_{L L}^{*}\right)=\arg \max E\left(\pi_{r L L}\right) \\
& E\left(\pi_{r H H}\right) \geq E\left(\pi_{r H L}\right) \\
& E\left(\pi_{r L L}\right) \geq E\left(\pi_{r L H}\right) \\
& E\left(\pi_{r H H}\right) \geq \pi_{r}^{0} \\
& E\left(\pi_{r L L}\right) \geq \pi_{r}^{0}
\end{array}
$$

The optimal profit of the retailer without the contract is $\pi_{r}^{0}$ called conserved profit. Eqs. (12) and (13) are participation constraints that can guarantee the retailer's profit no lesser than her conserved profit. Eq. (10) indicates the profit of retailer exerting $H$ level and $G_{H}$ contract is higher than the profit of choosing $H$ level and $G_{L}$ contract. Meanwhile, Eq. (11) shows the profit of the retailer with $L$ level and $G_{L}$ contract is much more than the profit under $L$ level and $G_{H}$ contract. Eqs. (10) and (11) are both incentive compatibility constraints to avoid the false information from the retailer, by which the retailer can maximize her profit. In Eq. (7), $E\left(\pi_{m H}\right)$ represents the expected profit of the manufacturer when the retailer with $H$ level accepts $G_{H}$ contract, while $E\left(\pi_{m H}\right)$ denotes the expected profit of the manufacturer if the retailer adopted $L$ level accepts contract.

Solving the above programming model with Lagrange multiplier method, we find that:

$$
w_{H}^{*}=\frac{4 \Delta\left(\phi-e_{H}\right)-3 \Delta^{2}+(\Delta+2 a)\left(c_{r}+3 c_{n}\right)}{8(\Delta+a)}
$$




$$
\begin{aligned}
& w_{L}^{*}=\frac{4 \Delta \phi+(\Delta+2 a)\left(c_{r}+3 c_{n}\right)-3 \Delta^{2}}{8(\Delta+a)}-\frac{\Delta\left(e_{L}-v e_{H}\right)}{2(1-v)(\Delta+a)} \\
& b_{H}^{*}=\frac{\Delta\left(\phi-e_{H}-w_{H}^{*}+3 a / 2\right)}{\Delta+2 a} \\
& b_{L}^{*}=\frac{\Delta\left(\phi-w_{L}^{*}+3 a / 2\right)}{\Delta+2 a}-\frac{[\Delta(1-v)-2 a v] e_{L}+2 a v e_{H}}{(1-v)(\Delta+2 a)}
\end{aligned}
$$

Substituting $w_{H}^{*}, w_{L}^{*}$ into Eqs. (16) and (17), we result in the optimal buy-back prices of the manufacturer without the government intervention:

$$
\begin{gathered}
T_{r H}^{*}=\frac{\left(b_{L}^{*}+e_{L}\right)^{2}-e_{L}^{2}+\left(\phi-w_{L}^{*}+a / 2\right)^{2}}{4}-\pi_{r}^{0} \\
T_{r H}^{*}=\frac{\left(b_{H}^{*}+e_{H}\right)^{2}+\left(\phi-w_{H}^{*}+a / 2\right)^{2}-\left(b_{L}^{*}+e_{H}\right)^{2}-\left(\phi-w_{L}^{*}+a / 2\right)^{2}}{4}+T_{r L}^{*}
\end{gathered}
$$

Substituting $w_{H}^{*}, w_{L}^{*}, b_{H}^{*}$ and $b_{L}^{*}$ into Eqs. (18) and (19), we obtain the optimal franchise fees

$$
\begin{aligned}
p_{H H}^{*} & =\frac{\phi+\mathrm{w}_{H}^{*}+a / 2}{2} \\
p_{L L}^{*} & =\frac{\phi+w_{L}^{*}+a / 2}{2}
\end{aligned}
$$

The optimal retail price of the CLSC without the RPM can be attained by substituting $w_{H}^{*}, w_{L}^{*}$ into Eqs. (20) and (21):

$$
\begin{gathered}
r_{H H}^{*}=\frac{b_{H}^{*}-e_{H}}{2} \\
r_{L L}^{*}=\frac{b_{L}^{*}-e_{L}}{2}
\end{gathered}
$$

Similarly, after the $b_{H}^{*}, b_{L}^{*}$ have been substituted into Eqs. (22) and (23), we obtain the optimal collection prices based on the retailer's collection effort level.

By solving Case 1,we can derive Proposition 1.

Proposition 1. (a)The optimal information screening contract $G_{L}$ are given by

$$
\begin{gathered}
b_{H}^{*}=\frac{\Delta\left(\phi-e_{H}-w_{H}^{*}+3 a / 2\right)}{\Delta+2 a}, w_{H}^{*}=\frac{4 \Delta\left(\phi-e_{H}\right)-3 \Delta^{2}+(\Delta+2 a)\left(c_{r}+3 c_{n}\right)}{8(\Delta+a)} \\
T_{r H}^{*}=\frac{\left(b_{H}^{*}+e_{H}\right)^{2}+\left(\phi-w_{H}^{*}+a / 2\right)^{2}-\left(b_{L}^{*}+e_{H}\right)^{2}-\left(\phi-w_{L}^{*}+a / 2\right)^{2}}{4}+T_{r L}^{*}
\end{gathered}
$$

(b) The optimal information screening contract $G_{L}$ are given by

$$
b_{L}^{*}=\frac{\Delta\left(\phi-w_{L}^{*}+3 a / 2\right)}{\Delta+2 a}-\frac{[\Delta(1-v)-2 a v] e_{L}+2 a v e_{H}}{(1-v)(\Delta+2 a)}
$$




$$
\begin{aligned}
& w_{L}^{*}=\frac{4 \Delta \phi+(\Delta+2 a)\left(c_{r}+3 c_{n}\right)-3 \Delta^{2}}{8(\Delta+a)}-\frac{\Delta\left(e_{L}-v e_{H}\right)}{2(1-v)(\Delta+a)}, \\
& T_{\mathrm{rL}}^{*}=\frac{\left(b_{L}^{*}+e_{L}\right)^{2}-e_{L}^{2}+\left(\phi-w_{L}^{*}+a / 2\right)^{2}}{4}-\pi_{r}^{0}
\end{aligned}
$$

(c) The optimal retail price and collection price are given by

$$
p_{H H}^{*}=\frac{\phi+\mathrm{w}_{H}^{*}+a / 2}{2}, r_{H H}^{*}=\frac{b_{H}^{*}-e_{H}}{2} ; p_{L L}^{*}=\frac{\phi+w_{L}^{*}+a / 2}{2}, r_{L L}^{*}=\frac{b_{L}^{*}-e_{L}}{2} .
$$

Proposition 1 implies that the information screening contract can ensure the manufacturer obtain the retailer's collection effort level.

Proposition 2.We have the following observations about information screening contracts.

$$
w_{H}^{*}<w_{L}^{*}, \mathrm{~b}_{H}^{*}>b_{L}^{*}, T_{\mathrm{rH}}^{*}>T_{r L}^{*}, \mathrm{p}_{H H}^{*}<p_{L L}^{*}, r_{H H}^{*}<r_{L L}^{*}
$$

Proof. $w_{L}^{*}-w_{H}^{*}=\frac{\Delta\left(e_{H}-e_{L}\right)}{2(\Delta+a)(1-v)}$, in terms of $e_{H}>e_{L}$, we obtain $w_{L}^{*}-w_{H}^{*}>0$, thus $w_{H}^{*}<w_{L}^{*} \quad ; \quad b_{H}^{*}-b_{L}^{*}=\frac{\Delta(1-v)\left(w_{L}^{*}-w_{H}^{*}-e_{H}\right)}{\Delta+2 a}+\frac{\Delta(1-v)+2 a v\left(e_{H}-e_{L}\right)}{(1-v)(\Delta+2 a)}$,we have known $w_{L}^{*}-w_{H}^{*}>0$ and $e_{H}>e_{L}$, so $b_{H}^{*}>b_{L}^{*} ; T_{r H}^{*}-T_{\mathrm{rL}}^{*}=\frac{\left(b_{H}^{* 2}-b_{L}^{* 2}\right)+\left(w_{L}^{*}-w_{H}^{*}\right)\left[2 \phi+a-\left(w_{H}^{*}+w_{L}^{*}\right)\right]}{4}$,fr om assumption (v) we know $\phi>p>w$,so $2 \phi+a-\left(w_{H}^{*}+w_{L}^{*}\right)$ and we get $T_{r H}^{*}-T_{\mathrm{rL}}^{*}>0 ; p_{L L}^{*}-\mathrm{p}_{H H}^{*}=\frac{w_{L}^{*}-w_{H}^{*}}{2}>0$, thus $p_{L L}^{*}>\mathrm{p}_{H H}^{*}$, Similarly, we can get $r_{H H}^{*}<r_{L L}^{*}$.

Proposition 2 indicates that the manufacturer would offer lower wholesale price and higher buyback price for the $\mathrm{H}$-type retailer to reward and stimulate the $\mathrm{H}$-type retailer. Meanwhile, to ensure its own profits, the manufacturer charge more franchise fee to H-type retailer than L-type retailer. Because of the lower wholesale price, the H-type retailer sales products at a lower retailer price. In addition, the $\mathrm{H}$-type retailer can collect the waste products from consumer at a lower price than the L-type retailer.

\section{Decision-making of the CLSC with RPM(Case 2)}

In this section, we investigate the impacts of RPM established by the government on the CLSC. Same as Case 1, the retailer's collection effort level is privately asymmetric information and the information screening contract is denoted as $\left\{G_{H}\left(b_{H}, w_{H}, T_{r H}\right), G_{L}\left(b_{L}, w_{L}, T_{r L}\right)\right\}$ in case 2. The RPM established by government is expressed as $\left(k, Q_{0}\right)$, where $Q_{0}$ is the target collection quantity and $k$ is the reward-penalty intensity to enhance the WEEE collection. Thus, the manufacturer be rewarded if the collection target is fulfilled; otherwise he will be penalized. In 
this case, the reward intensity is assumed the same as the penalty intensity for avoiding complicated calculation.

When the retailer with $H$ level chooses contract $G_{H}$, the expected profit of manufacturer can be expressed as:

$$
\begin{aligned}
E\left(\pi_{m H}\right)= & \int_{0}^{z_{H}}\left(\phi-p_{H H}+x\right)\left(w_{H}-c_{r}\right) f(x) d x+T_{r H}+k\left(Q_{H H}-Q_{0}\right) \\
& +\int_{z H}^{a}\left(\phi-p_{H H}+x-e_{H}-r_{H H}\right)\left(w_{H}-c_{n}\right) f(x) d x \\
& +\int_{z H}^{a}\left(e_{H}+r_{H H}\right)\left(w_{H}-c_{r}\right) f(x) d x-b_{H}\left(e_{H}+r_{H H}\right)
\end{aligned}
$$

In Eq. (24), $z_{H}=e_{H}+r_{H H}-\phi+p_{H H}$, if $0<x \leq z_{H}$, the new products can satisfy the market demand. Otherwise, if $z_{H}<x<a$, the market demand exceeds the collection quantity of WEEE, the remanufactured and new-manufactured products satisfy the market demand jointly.

Similarly, if the retailer with $L$ level chooses contract $G_{L}$, the manufacturer's expected profit can be formulated as:

$$
\begin{aligned}
E\left(\pi_{m L}\right)= & \int_{0}^{z_{L}}\left(\phi-p_{L L}+x\right)\left(w_{L}-c_{r}\right) f(x) d x+T_{r L}+k\left(Q_{L L}-Q_{0}\right) \\
& +\int_{z L}^{a}\left(\phi-p_{L L}+x-e_{L}-r_{L L}\right)\left(w_{L}-c_{n}\right) f(x) d x \\
& +\int_{z L}^{a}\left(e_{L}+r_{L L}\right)\left(w_{L}-c_{r}\right) f(x) d x-b_{L}\left(e_{L}+r_{L L}\right)
\end{aligned}
$$

In Eq. (25), $z_{L}=e_{L}+r_{L L}-\phi+p_{L L}$, if $0<x \leq z_{L}$, the remanufactured products are in sufficient quantities to satisfy the market demand. However, if $z_{L}<x<a$, remanufactured and new-manufactured products meet the market demand conjunctly.

If the retailer opts to contract $G_{H}$ under $H$ level, the expected profit of the retailer is

$$
\begin{aligned}
E\left(\pi_{r H H}\right)= & \left(b_{H}-r_{H H}\right)\left(e_{H}+r_{H H}\right)-e_{H}^{2} / 4 \\
& +\left(p_{H H}-w_{H}\right) \int_{0}^{a}\left(\phi-p_{H H}+x\right) d x-T_{r H}
\end{aligned}
$$

When the retailer is $H$ collection effort level but choosing contract $G_{L}$, the retailer's expected profit is denoted as:

$$
\begin{aligned}
E\left(\pi_{r H L}\right)= & \left(b_{L}-r_{H L}\right)\left(e_{H}+r_{H H}\right)-e_{H}^{2} / 4 \\
& +\left(p_{H L}-w_{L}\right) \int_{0}^{a}\left(\phi-p_{H L}+x\right) d x-T_{r L}
\end{aligned}
$$

If the retailer chooses contract $G_{L}$ under $L$ collection effort level, we find her expected profit can be expressed as:

$$
\begin{aligned}
E\left(\pi_{r L L}\right)= & \left(b_{L}-r_{L L}\right)\left(e_{L}+r_{L L}\right)-e_{L}^{2} / 4 \\
& +\left(p_{L L}-w_{L}\right) \int_{0}^{a}\left(\phi-p_{L L}+x\right) d x-T_{r L}
\end{aligned}
$$


If the retailer's collection effort is $L$ level, and chooses contract $G_{H}$, we find her expected profit is

$$
\begin{aligned}
E\left(\pi_{r L H}\right)= & \left(b_{H}-r_{L H}\right)\left(e_{L}+r_{L H}\right)-e_{L}^{2} / 4 \\
& +\left(p_{L H}-w_{H}\right) \int_{0}^{a}\left(\phi-p_{L H}+x\right) d x-T_{r H}
\end{aligned}
$$

In the CLSC under random demand environment with RPM, when the retailer's collection effort level information is asymmetric, the manufacturer seeks to maximize the expected profit which can be expressed as:

$$
\begin{array}{ll}
\max & E\left(\pi_{m}\right)=v E\left(\pi_{m H}\right)+(1-v) E\left(\pi_{m L}\right) \\
\text { s.t. } & \left(p_{H H}^{* *}, r_{H H}^{* *}\right)=\arg \max E\left(\pi_{r H H}\right) \\
& \left(p_{L L}^{* *}, r_{L L}^{* *}\right)=\arg \max E\left(\pi_{r L L}\right) \\
& E\left(\pi_{r H H}\right) \geq E\left(\pi_{r H L}\right) \\
& E\left(\pi_{r L L}\right) \geq E\left(\pi_{r L H}\right) \\
& E\left(\pi_{r H H}\right) \geq \pi_{r}^{0} \\
& E\left(\pi_{r L L}\right) \geq \pi_{r}^{0}
\end{array}
$$

$\pi_{r}^{0}$ is the optimal profit of the retailer without the contract, which is called conserved profit. Eqs. (35) and (36) are participation constraints ensuring the retailer accept the contract. Eqs. (33) and (34) are incentive compatibility constraints restricting the retailer only when she chooses the same type contract as the collective effort level can she gains higher profit than exerting other contracts. The incentive compatibility constraints enable the manufacturer obtain the collection effort level information from the retailer. Eq. (33) indicates the profit of the retailer with $H$ collection effort level and $G_{H}$ contract is much more than the profit from choosing $H$ collection effort level but $G_{H}$ contract. Meanwhile, Eq. (34) shows the profit of the retailer exerting $L$ collection effort level and $G_{L}$ contract is higher than the case under $L$ collection effort level but $G_{H}$ contract.

From the solution of the above programming model with Lagrange multiplier method, we have

$$
\begin{aligned}
& w_{H}^{* *}=\frac{4 \Delta\left(\phi-e_{H}-k\right)-3 \Delta^{2}+(\Delta+2 a)\left(c_{r}+3 c_{n}\right)}{8(\Delta+a)} \\
& w_{L}^{* *}=\frac{4 \Delta(\phi-k)-3 \Delta^{2}+(\Delta+2 a)\left(c_{r}+3 c_{n}\right)}{8(\Delta+a)}-\frac{\Delta\left(e_{L}-v e_{H}\right)}{2(1-v)(\Delta+a)} \\
& b_{H}^{* *}=\frac{\Delta\left(\phi-e_{H}-w_{H}^{* *}+3 a / 2\right)+2 a k}{\Delta+2 a} \\
& b_{L}^{* *}=\frac{\Delta\left(\phi-w_{L}^{* *}+3 a / 2\right)+2 a k}{\Delta+2 a}-\frac{[\Delta(1-v)-2 a v] e_{L}+2 a v e_{L}}{(1-v)(\Delta+2 a)}
\end{aligned}
$$

The substitution of $w_{H}^{* *}, w_{L}^{* *}$ into Eqs. (39)and (40) gets the optimal buy-back price of the manufacturer with RPM. 


$$
\begin{gathered}
T_{\mathrm{rL}}^{* *}=\frac{\left(b_{L L}^{* *}+e_{L}\right)^{2}-e_{L}^{2}+\left(\phi-w_{L}^{* *}+a / 2\right)^{2}}{4}-\pi_{r}^{0} \\
T_{r H}^{* *}=\frac{\left(b_{H}^{* *}+e_{H}\right)^{2}+\left(\phi-w_{H}^{* *}+a / 2\right)^{2}-\left(b_{L}^{* *}+e_{H}\right)^{2}-\left(\phi-w_{L}^{* *}+a / 2\right)^{2}}{4}+T_{\mathrm{rL}}^{* *}
\end{gathered}
$$

Substituting $w_{H}^{* *}, w_{L}^{* *}, b_{H}^{* *}$ and $b_{L}^{* *}$ into Eqs.(41) and(42) results in the optimal franchise fee with RPM :

$$
\begin{array}{r}
p_{H H}^{* *}=\frac{\phi+w_{H}^{* *}+a / 2}{2} \\
p_{L L}^{* *}=\frac{\phi+w_{L}^{* *}+a / 2}{2}
\end{array}
$$

Substitution of $w_{H}^{* *}, w_{L}^{* *}$ into Eqs.(43)and (44) gets the optimal retail price of the retailer according to the real collection effort level with the RPM:

$$
\begin{gathered}
r_{H H}^{* *}=\frac{b_{H}^{* *}-e_{H}}{2} \\
r_{L L}^{* *}=\frac{b_{L}^{* *}-e_{L}}{2}
\end{gathered}
$$

Lastly, substituting $b_{H}^{* *}, b_{L}^{* *}$, into Eqs. (45) and (46) gets the optimal collection price based on the retailer's collection effort level when the government establishes the RPM for the manufacturer.

By solving Case 2,we can derive Lemma 2.

Proposition 3. (a)Under PRM, the optimal information screening contract $G_{H}$ are given by

$$
\begin{gathered}
w_{H}^{* *}=\frac{4 \Delta\left(\phi-e_{H}-k\right)-3 \Delta^{2}+(\Delta+2 a)\left(c_{r}+3 c_{n}\right)}{8(\Delta+a)}, b_{H}^{* *}=\frac{\Delta\left(\phi-e_{H}-w_{H}^{* *}+3 a / 2\right)+2 a k}{\Delta+2 a} \\
T_{r H}^{* *}=\frac{\left(b_{H}^{* *}+e_{H}\right)^{2}+\left(\phi-w_{H}^{* *}+a / 2\right)^{2}-\left(b_{L}^{* *}+e_{H}\right)^{2}-\left(\phi-w_{L}^{* *}+a / 2\right)^{2}}{4}+T_{\mathrm{rL}}^{* *}
\end{gathered}
$$

(b) Under PRM, the optimal information screening contract $G_{L}$ are given by

$$
\begin{gathered}
w_{L}^{* *}=\frac{4 \Delta(\phi-k)-3 \Delta^{2}+(\Delta+2 a)\left(c_{r}+3 c_{n}\right)}{8(\Delta+a)}-\frac{\Delta\left(e_{L}-v e_{H}\right)}{2(1-v)(\Delta+a)} \\
b_{L}^{* *}=\frac{\Delta\left(\phi-w_{L}^{* *}+3 a / 2\right)+2 a k}{\Delta+2 a}-\frac{[\Delta(1-v)-2 a v] e_{L}+2 a v e_{L}}{(1-v)(\Delta+2 a)} \\
T_{\mathrm{rL}}^{* *}=\frac{\left(b_{L L}^{* *}+e_{L}\right)^{2}-e_{L}^{2}+\left(\phi-w_{L}^{* *}+a / 2\right)^{2}}{4}-\pi_{r}^{0}
\end{gathered}
$$




\section{Analysis of the two cases}

Proposition 4. If the government establishes RPM for the manufacturer, the wholesale price and retail price are lower than those without RPM.

Proof. Comparing Eq. (37) with Eq.(14), we have $w_{H}^{* *}-w_{H}^{*}=-\Delta k / 2(\Delta+a)<0$. The $w_{L}^{* *}-w_{L}^{*}=-\Delta k / 2(\Delta+a)<0$ can be got from the comparison of Eq.(38) with Eq.(15). We can find from $w_{H}^{* *}-w_{H}^{*}<0$ and $w_{L}^{* *}-w_{L}^{*}<0$ that the wholesale price is lower than that in the case which the government establishes RPM for the manufacturer. Then again, we have $p_{H H}^{* *}-p_{H H}^{*}=\left(w_{H}^{* *}-w_{H}^{*}\right) / 2<0$ from the comparison of Eq. (43) with Eq. (20) and $p_{L L}^{* *}-p_{L L}^{*}=\left(w_{L}^{* *}-w_{L}^{*}\right) / 2<0$ from the comparison of Eq. (44) with Eq. (21). So the price of the retail lower than that in the condition which the government establishes RPM for the manufacturer can be obtained.

Proposition 4 shows that under RPM the manufacturer offers lower wholesale price to the retailer and the retailer to sell more products will provides a lower retailer to consumers. The RPM can reduce the wholesale price and retail price on the market.

Proposition 5. The buy-back price, collection price and collection quantity under RPM are higher than those without RPM.

Proof. $b_{H}^{* *}-b_{H}^{*}=k(\Delta+2 a) / 2(\Delta+a)>0$ and $b_{L}^{* *}-b_{L}^{*}=k(\Delta+2 a) / 2(\Delta+a)>0$ can be got by the comparison of Eq. (39) with Eq. (16) and Eq. (40) with Eq. (17) respectively. Then the buy-back price is higher than the case without RPM. Comparing Eq. (45) with Eq. (22) and Eq. (46) with Eq. (23) respectively, the $r_{H H}^{* *}-r_{H H}^{*}=\left(b_{H}^{* *}-b_{H}^{*}\right) / 2>0$ and $r_{L L}^{* *}-r_{L L}^{*}=\left(b_{L}^{* *}-b_{L}^{*}\right) / 2>0$ can be attained, hence the collection price is higher than that in the case under RPM. Based on Assumption (vi), we know $Q_{H H}^{* *}-Q_{H H}^{*}=r_{H H}^{* *}-r_{H H}^{*}$, so $Q_{H H}^{* *}-Q_{H H}^{*}>0$. Similarly, $Q_{L L}^{* *}-Q_{L L}^{*}=r_{L L}^{* *}-r_{L L}^{*}$, thus $Q_{L L}^{* *}-Q_{L L}^{*}>0$, so the collection quantity is higher than that under the case without RPM.

Proposition 5 indicates that under the PRM, the manufacturer would raise the buy-back price to stimulate the retailer's collection effort and the retailer would raise the collection price to collect more waste products corresponding. Thus, the implementation of RPM can increase the collection quantity.

Proposition 6. The franchise fee in the case with RPM is higher than that without RPM.

Proof. From. (41) and (18), we have

$$
T_{r L}^{* *}-T_{\mathrm{rH}}^{*}=\left[\left(b_{L}^{* *}+e_{L}\right)^{2}-\left(b_{L}^{*}+e_{L}\right)^{2}+\left(\phi-w_{L}^{* *}+a / 2\right)^{2}-\left(\phi-w_{L}^{*}+a / 2\right)^{2}\right] / 4,
$$


since $b_{L}^{* *}>b_{L}^{*}$ and $w_{L}^{* *}<w_{L}^{*}, T_{r L}^{* *}-T_{r L}^{*}>0$. Similarly, subtract Eq.(19) from Eq.(42) and we get

$$
\begin{gathered}
T_{r H}^{* *}-T_{r H}^{*}=\frac{K(\Delta+2 a)\left(b_{H}^{* *}+b_{H}^{*}+2 e^{L}\right) / 2(\Delta+a)+\left(\phi-w_{H}^{* *}+a / 2\right)^{2}-\left(\phi-w_{H}^{*}+a / 2\right)^{2}}{4} \\
T_{r H}^{* *}-T_{\mathrm{rH}}^{* *}=\frac{K(\Delta+2 a)\left(b_{H}^{* *}+b_{H}^{*}+2 e_{\mathrm{L}}\right) / 2(\Delta+a)+\left(\phi-w_{H}^{* *}+a / 2\right)^{2}-\left(\phi-w_{H}^{*}+a / 2\right)^{2}}{4},
\end{gathered}
$$

due to $w_{H}^{* *}<w_{H}^{*}$ and $T_{r H}^{* *}-T_{r H}^{*}>0$. The franchise fee with RPM for the manufacturer is higher than that without RPM can be obtained in accordance with the above results.

From Proposition4 and 5, we know that the manufacturer reduce the wholesale price and increase the buy-back price under the RPM. So Proposition 6 indicates the manufacturer would ensure its own profits by charging more franchise fee to the retailer under the RPM.

\section{Numerical examples}

\subsection{Analysis of Case 1}

We now study the asymmetric information CLSC further. Let

$$
c_{n}=60, c_{r}=45, a=4, \phi=120, e_{H}=10, e_{L}=7, \pi_{r}^{0}=400, \Delta=c_{n}-c_{r}=15 ;
$$

and $v \in\{0.1,0.2,0.3,0.4,0.5,0.6,0.7,0.8,0.9\}$. Table 1 shows the optimal decision-making of CLSC with different $v$ and we can find:

(1) The manufacturer offers a fixed wholesale price to $w_{H}^{*}$ the $H$ retailer no matter how the $v$ changes. But, the manufacturer will provide the $L$ retailer $w_{L}^{*}$ considering the change of $v$. In Eq. (14), taking the first derivative of $w_{H}^{*}$ respect to $v$ and get $\frac{d w_{H}^{*}}{d v}=0$, which shows that $w_{H}^{*}$ won't change with $v$. In Eq. (15), taking the first derivative of $w_{L}^{*}$ with respect to $v$ and we have $\frac{d w_{L}^{*}}{d v}=\frac{\Delta\left(e_{H}-e_{L}\right)}{2(\Delta+a)(1-v)^{2}}>0, \frac{d w_{L}^{*}}{d v}>0$ due to $e_{H}>e_{L}$, which implies the wholesale price $w_{L}^{*}$ increases with $v$. So when the manufacturer offers wholesale price $w_{L}^{*}$ for the $L$ retailer, the manufacturer will take the probability of being $H$ retailer. Under the same $v, w_{H}^{*}<w_{L}^{*}$ means the retailer chooses $H$ collection effort level can enjoy lower wholesale price. From Eqs. (20) and (21), we know the retail price is the positive function of the wholesale price which implies the changing trend of the retail price is the same as that of the wholesale price.

Table 1. The optimal decision results changing with the parameter $v$

\begin{tabular}{clllllllll}
\hline & $v$ & \multicolumn{10}{c}{0} & & & & \\
\cline { 2 - 9 } & 0.1 & 0.2 & 0.3 & 0.4 & 0.5 & 0.6 & 0.7 & 0.8 & 0.9 \\
\hline$w_{H}^{*}$ & 73.026 & 73.026 & 73.026 & 73.026 & 73.026 & 73.026 & 73.026 & 73.026 & 73.026
\end{tabular}




\begin{tabular}{|c|c|c|c|c|c|c|c|c|c|}
\hline$w_{L}^{*}$ & 74.342 & 74.420 & 74.507 & 74.605 & 74.718 & 74.848 & 75.000 & 75.179 & 75.395 \\
\hline$b_{H}^{*}$ & 28.026 & 28.026 & 28.026 & 28.026 & 28.026 & 28.026 & 28.026 & 28.026 & 28.026 \\
\hline$b_{L}^{*}$ & 29.009 & 28.890 & 28.757 & 28.605 & 28.432 & 28.233 & 28.000 & 27.725 & 27.395 \\
\hline$T_{r H}^{*}$ & 479.727 & 475.751 & 471.290 & 466.249 & 460.508 & 453.911 & 446.250 & 437.246 & 426.512 \\
\hline$T_{r L}^{*}$ & 492.593 & 492.771 & 492.971 & 493.198 & 493.458 & 493.757 & 494.106 & 494.519 & 495.014 \\
\hline$r_{H H}^{*}$ & 97.513 & 97.513 & 97.513 & 97.513 & 97.513 & 97.513 & 97.513 & 97.513 & 97.513 \\
\hline$r_{L L}^{*}$ & 98.171 & 98.210 & 98.253 & 98.303 & 98.359 & 98.424 & 98.500 & 98.590 & 98.697 \\
\hline$p_{H H}^{*}$ & 9.013 & 9.013 & 9.013 & 9.013 & 9.013 & 9.013 & 9.013 & 9.013 & 9.013 \\
\hline$p_{L L}^{*}$ & 11.004 & 10.945 & 10.878 & 10.803 & 10.716 & 10.616 & 10.500 & 10.362 & 10.197 \\
\hline$Q_{H H}^{*}$ & 19.013 & 19.013 & 19.013 & 19.013 & 19.013 & 19.013 & 19.013 & 19.013 & 19.013 \\
\hline$Q_{L L}^{*}$ & 18.004 & 17.945 & 17.878 & 17.803 & 17.716 & 17.616 & 17.500 & 17.362 & 17.197 \\
\hline$E\left(\pi_{m H}^{*}\right)$ & 541.270 & 541.448 & 541.648 & 541.875 & 542.134 & 542.434 & 542.783 & 543.196 & 543.691 \\
\hline$E\left(\pi_{m L}^{*}\right)$ & 541.838 & 541.813 & 541.770 & 541.704 & 541.605 & 541.460 & 541.250 & 540.944 & 540.493 \\
\hline$E\left(\pi_{r H H}^{*}\right)$ & 443.513 & 443.335 & 443.135 & 442.908 & 442.649 & 442.349 & 442.000 & 441.587 & 441.092 \\
\hline$E\left(\pi_{r L L}^{*}\right)$ & 400.000 & 400.000 & 400.000 & 400.000 & 400.000 & 400.000 & 400.000 & 400.000 & 400.000 \\
\hline
\end{tabular}

(2) The manufacturer provides a fixed buy-back price $b_{H}^{*}$ to the $H$ retailer no matter how $v$ changes. When the retailer exerts $L$ collection effort level, $w_{L}^{*}$ will change with $v$. In Eq. (16), taking the first derivative of $b_{H}^{*}$ respect to $v$, we have $\frac{d b_{H}^{*}}{d v}=0$ that implies $v$ does not impact $b_{H}^{*}$. From Eq. (17), taking the first derivative of $b_{L}^{*}$ respect to $v$ obtains $\frac{d b_{L}^{*}}{d v}=-\frac{2 a\left(e_{H}-e_{L}\right)}{(\Delta+2 a)(1-v)^{2}}<0$, so the buy-back price $b_{L}^{*}$ decreases with $v$ when the retailer chooses $L$ collection effort level. For the $L$ retailer, the manufacturer offers lower buy-back price as the $v$ increase. Based on Eqs. (22), (23) and Assumption (vi), we know the collection price and collection quantity are the positive correlation of the buy-back price which means the collection price and collection quantity has the same changing trend with the buy-back price.

(3) The franchise fee $T_{r H}^{*}$ increases with $v$, while $T_{r L}^{*}$ decreases with $v$.

(4) When the retailer chooses $G_{H}$, the expected profit of the manufacturer increases with $v$, however, the expected profit of the retailer decreases with $v$. When the retailer accepts $G_{L}$, the 
expected profit of the manufacturer decreases with $v$, and the expected profit of the retailer is the conserved profit.

\subsection{Analysis of Case 2}

To indicate the influence of RPM on the WEEE collection, we employ the same parameters as that in Section 6.1:

$$
c_{n}=60, c_{r}=45, a=4, \phi=120, e_{H}=10, e_{L}=7, \pi_{r}^{0}=400, \Delta=c_{n}-c_{v}, \text { let } k \in\{10,20,30,40\},
$$

$Q_{0}=25$. The numerical results of the CLSC with RPM are shown in Table 2 and Figure 3-10.

(1) Table 2 shows the optimal decision-making of the CLSC with RPM. Compared with Table 1, we can find that: $w_{H}^{* *}<w_{H}^{*}, w_{L}^{* *}<w_{L}^{*}, p_{H H}^{* *}<p_{H H}^{*}, p_{L L}^{* *}<p_{L L}^{*}$. Figure 3 and Figure 4 show that the wholesale price $w_{H}^{* *}$ and $w_{L}^{* *}$, retail price $p_{H H}^{* *}$ and $p_{L L}^{* *}$ decrease with rewardpenalty intensity $k$. It can be proofed as follows. Taking the first derivative of Eq. (37) with respect to $\mathrm{k}$ results in $\frac{d w_{H}^{* *}}{d k}=-\frac{\Delta}{2(\Delta+a)}<0 \quad ; \quad$ Similarly, $\quad \frac{d w_{L}^{* *}}{d k}=-\frac{\Delta}{2(\Delta+a)}<0$, $\frac{d p_{H H}^{* *}}{d k}=-\frac{\Delta}{2(\Delta+a)}<0, \frac{d p_{L L}^{* *}}{d k}=-\frac{\Delta}{2(\Delta+a)}<0$ can be got by taking the first derivative of Eqs. (38), (43) and (44) respectively.

Combining the results above, we have that the wholesale price and the retail price decrease with reward-penalty intensity and they are lower than that without RPM. The decrease in retail price benefits the consumer and enlarges the demand of new products. Therefore, the RPM can decrease retail price and benefit the consumers.

Table 2. The optimal decision results vs. $k$ and $v$

\begin{tabular}{|c|c|c|c|c|c|c|c|c|c|}
\hline \multirow{2}{*}{$k$} & \multicolumn{9}{|l|}{$v$} \\
\hline & 0.1 & 0.2 & 0.3 & 0.4 & 0.5 & 0.6 & 0.7 & 0.8 & 0.9 \\
\hline \multicolumn{10}{|c|}{$w_{H}^{* *}$} \\
\hline 10 & 69.079 & 69.079 & 69.079 & 69.079 & 69.079 & 69.079 & 69.079 & 69.079 & 69.079 \\
\hline 20 & 65.132 & 65.132 & 65.132 & 65.132 & 65.132 & 65.132 & 65.132 & 65.132 & 65.132 \\
\hline 30 & 61.184 & 61.184 & 61.184 & 61.184 & 61.184 & 61.184 & 61.184 & 61.184 & 61.184 \\
\hline 40 & 57.237 & 57.237 & 57.237 & 57.237 & 57.237 & 57.237 & 57.237 & 57.237 & 57.237 \\
\hline \multicolumn{10}{|c|}{$w_{L}^{* *}$} \\
\hline 10 & 70.395 & 70.559 & 70.771 & 71.053 & 71.447 & 72.039 & 73.026 & 75.000 & 80.921 \\
\hline 20 & 66.447 & 66.612 & 66.823 & 67.105 & 67.500 & 68.092 & 69.079 & 71.053 & 76.974 \\
\hline 30 & 62.500 & 62.664 & 62.876 & 63.158 & 63.553 & 64.145 & 65.132 & 67.105 & 73.026 \\
\hline 40 & 58.553 & 58.717 & 58.929 & 59.211 & 59.605 & 60.197 & 61.184 & 63.158 & 69.079 \\
\hline \multicolumn{10}{|c|}{$b_{H}^{* *}$} \\
\hline 10 & 34.079 & 34.079 & 34.079 & 34.079 & 34.079 & 34.079 & 34.079 & 34.079 & 34.079 \\
\hline 20 & 40.132 & 40.132 & 40.132 & 40.132 & 40.132 & 40.132 & 40.132 & 40.132 & 40.132 \\
\hline 30 & 46.184 & 46.184 & 46.184 & 46.184 & 46.184 & 46.184 & 46.184 & 46.184 & 46.184 \\
\hline 40 & 52.237 & 52.237 & 52.237 & 52.237 & 52.237 & 52.237 & 52.237 & 52.237 & 52.237 \\
\hline \multicolumn{10}{|c|}{$b_{L}^{* *}$} \\
\hline 10 & 35.061 & 34.809 & 34.485 & 34.053 & 33.447 & 32.539 & 31.026 & 28.000 & 18.921 \\
\hline 20 & 41.114 & 40.862 & 40.538 & 40.105 & 39.500 & 38.592 & 37.079 & 34.053 & 24.974 \\
\hline
\end{tabular}




\begin{tabular}{|c|c|c|c|c|c|c|c|c|c|}
\hline 30 & 47.167 & 46.914 & 46.590 & 46.158 & 45.553 & 44.645 & 43.132 & 40.105 & 31.026 \\
\hline 40 & 53.219 & 52.967 & 52.643 & 52.211 & 51.605 & 50.697 & 49.184 & 46.158 & 37.079 \\
\hline \multicolumn{10}{|c|}{$T_{r H}^{* *}$} \\
\hline 10 & 708.306 & 708.684 & 709.17 & 709.819 & 710.727 & 712.089 & 714.358 & 718.898 & 732.516 \\
\hline 20 & 950.127 & 950.505 & 950.992 & 951.64 & 952.548 & 953.91 & 956.18 & 960.719 & 974.338 \\
\hline 30 & 1218.056 & 1218.435 & 1218.921 & 1219.57 & 1220.477 & 1221.839 & 1224.109 & 1228.649 & 1242.267 \\
\hline 40 & 1512.094 & 1512.472 & 1512.958 & 1513.607 & 1514.515 & 1515.877 & 1518.146 & 1522.686 & 1536.304 \\
\hline \multicolumn{10}{|c|}{$T_{r L}^{* *}$} \\
\hline 10 & 695.816 & 686.291 & 674.111 & 657.988 & 635.64 & 602.606 & 548.856 & 446.25 & 177.595 \\
\hline 20 & 938.014 & 927.401 & 913.823 & 895.834 & 870.875 & 833.925 & 773.648 & 657.988 & 350.171 \\
\hline 30 & 1206.319 & 1194.619 & 1179.642 & 1159.789 & 1132.218 & 1091.353 & 1024.548 & 895.834 & 548.856 \\
\hline 40 & 1500.733 & 1487.945 & 1471.569 & 1449.851 & 1419.67 & 1374.888 & 1301.556 & 1159.789 & 773.648 \\
\hline \multicolumn{10}{|c|}{$r_{H H}^{* *}$} \\
\hline 10 & 12.039 & 12.039 & 12.039 & 12.039 & 12.039 & 12.039 & 12.039 & 12.039 & 12.039 \\
\hline 20 & 15.066 & 15.066 & 15.066 & 15.066 & 15.066 & 15.066 & 15.066 & 15.066 & 15.066 \\
\hline 30 & 18.092 & 18.092 & 18.092 & 18.092 & 18.092 & 18.092 & 18.092 & 18.092 & 18.092 \\
\hline 40 & 21.118 & 21.118 & 21.118 & 21.118 & 21.118 & 21.118 & 21.118 & 21.118 & 21.118 \\
\hline \multicolumn{10}{|c|}{$r_{L L}^{* *}$} \\
\hline 10 & 14.031 & 13.905 & 13.742 & 13.526 & 13.224 & 12.77 & 12.013 & 10.5 & 5.961 \\
\hline 20 & 17.057 & 16.931 & 16.769 & 16.553 & 16.25 & 15.796 & 15.039 & 13.526 & 8.987 \\
\hline 30 & 20.083 & 19.957 & 19.795 & 19.579 & 19.276 & 18.822 & 18.066 & 16.553 & 12.013 \\
\hline 40 & 23.11 & 22.984 & 22.821 & 22.605 & 22.303 & 21.849 & 21.092 & 19.579 & 15.039 \\
\hline \multicolumn{10}{|c|}{$p_{H H}^{* *}$} \\
\hline 10 & 95.539 & 95.539 & 95.539 & 95.539 & 95.539 & 95.539 & 95.539 & 95.539 & 95.539 \\
\hline 20 & 93.566 & 93.566 & 93.566 & 93.566 & 93.566 & 93.566 & 93.566 & 93.566 & 93.566 \\
\hline 30 & 91.592 & 91.592 & 91.592 & 91.592 & 91.592 & 91.592 & 91.592 & 91.592 & 91.592 \\
\hline 40 & 89.618 & 89.618 & 89.618 & 89.618 & 89.618 & 89.618 & 89.618 & 89.618 & 89.618 \\
\hline \multicolumn{10}{|c|}{$p_{L L}^{* *}$} \\
\hline 10 & 96.197 & 96.28 & 96.385 & 96.526 & 96.724 & 97.02 & 97.513 & 98.5 & 101.461 \\
\hline 20 & 94.224 & 94.306 & 94.412 & 94.553 & 94.75 & 95.046 & 95.539 & 96.526 & 99.487 \\
\hline 30 & 92.25 & 92.332 & 92.438 & 92.579 & 92.776 & 93.072 & 93.566 & 94.553 & 97.513 \\
\hline 40 & 90.276 & 90.359 & 90.464 & 90.605 & 90.803 & 91.099 & 91.592 & 92.579 & 95.539 \\
\hline \multicolumn{10}{|c|}{$Q_{H H}^{* *}$} \\
\hline 10 & 22.039 & 22.039 & 22.039 & 22.039 & 22.039 & 22.039 & 22.039 & 22.039 & 22.039 \\
\hline 20 & 25.066 & 25.066 & 25.066 & 25.066 & 25.066 & 25.066 & 25.066 & 25.066 & 25.066 \\
\hline 30 & 28.092 & 28.092 & 28.092 & 28.092 & 28.092 & 28.092 & 28.092 & 28.092 & 28.092 \\
\hline 40 & 31.118 & 31.118 & 31.118 & 31.118 & 31.118 & 31.118 & 31.118 & 31.118 & 31.118 \\
\hline \multicolumn{10}{|c|}{$Q_{L L}^{* *}$} \\
\hline 10 & 21.031 & 20.905 & 20.742 & 20.526 & 20.224 & 19.77 & 19.013 & 17.5 & 12.961 \\
\hline 20 & 24.057 & 23.931 & 23.769 & 23.553 & 23.25 & 22.796 & 22.039 & 20.526 & 15.987 \\
\hline 30 & 27.083 & 26.957 & 26.795 & 26.579 & 26.276 & 25.822 & 25.066 & 23.553 & 19.013 \\
\hline 40 & 30.11 & 29.984 & 29.821 & 29.605 & 29.303 & 28.849 & 28.092 & 26.579 & 22.039 \\
\hline \multicolumn{10}{|c|}{$E\left(\pi_{m H}^{* *}\right)$} \\
\hline 10 & 487.454 & 487.832 & 488.319 & 488.967 & 489.875 & 491.237 & 493.507 & 498.046 & 511.664 \\
\hline 20 & 463.901 & 464.28 & 464.766 & 465.414 & 466.322 & 467.684 & 469.954 & 474.493 & 488.112 \\
\hline 30 & 470.612 & 470.99 & 471.477 & 472.125 & 473.033 & 474.395 & 476.664 & 481.204 & 494.822 \\
\hline 40 & 507.586 & 507.964 & 508.45 & 509.099 & 510.007 & 511.368 & 513.638 & 518.178 & 531.796 \\
\hline \multicolumn{10}{|c|}{$E\left(\pi_{m L}^{* *}\right)$} \\
\hline 10 & 488.023 & 487.954 & 487.789 & 487.434 & 486.678 & 484.975 & 480.625 & 466.25 & 377.73 \\
\hline 20 & 464.47 & 464.402 & 464.237 & 463.882 & 463.125 & 461.423 & 457.072 & 442.697 & 354.178 \\
\hline 30 & 471.181 & 471.112 & 470.947 & 470.592 & 469.836 & 468.133 & 463.783 & 449.408 & 360.888 \\
\hline 40 & 508.154 & 508.086 & 507.921 & 507.566 & 506.809 & 505.107 & 500.757 & 486.382 & 397.862 \\
\hline
\end{tabular}




\begin{tabular}{|c|c|c|c|c|c|c|c|c|c|}
\hline \multicolumn{10}{|c|}{$E\left(\pi_{r H H}^{* *}\right)$} \\
\hline 10 & 452.592 & 452.214 & 451.727 & 451.079 & 450.171 & 448.809 & 446.539 & 442 & 428.382 \\
\hline 20 & 461.671 & 461.293 & 460.806 & 460.158 & 459.25 & 457.888 & 455.618 & 451.079 & 437.461 \\
\hline 30 & 470.75 & 470.372 & 469.885 & 469.237 & 468.329 & 466.967 & 464.697 & 460.158 & 446.539 \\
\hline 40 & 479.829 & 479.451 & 478.964 & 478.316 & 477.408 & 476.046 & 473.776 & 469.237 & 455.618 \\
\hline \multicolumn{10}{|c|}{$E\left(\pi_{r L L}^{* *}\right)$} \\
\hline 10 & 400 & 400 & 400 & 400 & 400 & 400 & 400 & 400 & 400 \\
\hline 20 & 400 & 400 & 400 & 400 & 400 & 400 & 400 & 400 & 400 \\
\hline 30 & 400 & 400 & 400 & 400 & 400 & 400 & 400 & 400 & 400 \\
\hline 40 & 400 & 400 & 400 & 400 & 400 & 400 & 400 & 400 & 400 \\
\hline
\end{tabular}

(2) Figures 5, 6 and 7 show that the buy-back price $b_{H}^{* *}$ and $b_{L}^{* *}$, the collection price $r_{H H}^{* *}$ and $r_{L L}^{* *}$, and the collection quantity $Q_{H H}^{* *}$ and $Q_{L L}^{* *}$ increase with reward-penalty intensity $k$. The proof is as follows: Taking the first derivative of Eq. (39) obtains $\frac{d b_{H}^{* *}}{d k}=\frac{\Delta+2 a}{2 \Delta+2 a}>0$. Similarly, taking the first derivative of Eq. (40) obtains $\frac{d b_{L}^{* *}}{d k}=\frac{\Delta+2 a}{2 \Delta+2 a}>0$. From Eqs. (45) and (46), we know the collection price is the positive correlation of the buy-back price and the collection quantity is the positive function of the collection price according to Assumption (vi). Obviously, the collection price, the collection quantity and buy-back price have the same trends as rewardpenalty intensity changes. Comparing Table 2 with Table 1 , we find $b_{H}^{* *}>b_{H}^{*}, b_{L}^{* *}>b_{L}^{*}, \mathrm{r}_{H H}^{* *}>r_{H H}^{*}$, $\mathrm{r}_{L L}^{* *}>r_{L L}^{*}, \mathrm{Q}_{H H}^{* *}>Q_{H H}^{*}$ and $\mathrm{Q}_{L L}^{* *}>Q_{L L}^{*}$ which indicate that the buy-back price, the collection price and the collection quantity with RPM are higher than that without RPM. The phenomenon shows the manufacturer enhances the buy-back price while the retailer increases the collection price, which improves the collection quantity. Thus, the RPM can lead the collection of WEEE effectively.
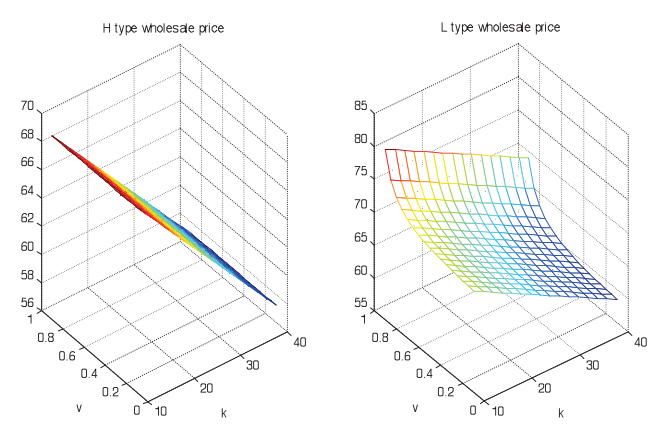

Figure 3. The wholesale price $w_{H}^{* *}$ and $w_{L}^{* *}$ vs. $k$ and $v$ 

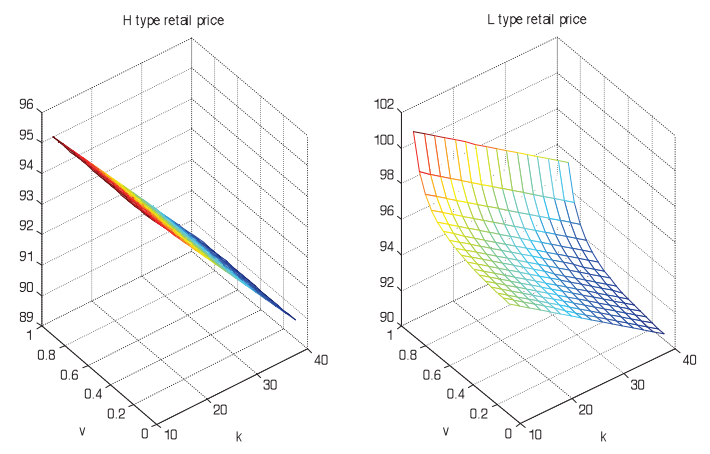

Figure 4. The retail price $p_{H H}^{* *}$ and $p_{L L}^{* *}$ vs. $k$ and $v$

(3) Figure 8 shows the franchise fee $T_{r H}^{* *}$ and $T_{r L}^{* *}$ increase with reward-penalty intensity. Since

$$
\partial T_{r L}^{* *} / \partial k=\left[\left(b_{L}^{* *}+e_{L}\right)(\Delta+2 a)+\Delta\left(\phi-w_{L}^{* *}+a / 2\right)\right] /(4 \Delta+4 a)>0 \quad \text { and }
$$
$\partial T_{r H}^{* *} / \partial k=\left[\left(b_{H}^{* *}+e_{L}\right)(\Delta+2 a)+\Delta\left(\phi-w_{H}^{* *}+a / 2\right)\right] /(4 \Delta+4 a)>0$, the franchise fee $T_{r H}^{* *}$ and $T_{r L}^{* *}$ increase with $k$. Comparing Table 2 with Table 1, we find $T_{r L}^{* *}>T_{r L}^{*}, T_{r H}^{* *}>T_{r H}^{*}$ which indicate the manufacturer charges more franchise fee under the RPM than that without RPM. In the context of RPM, the manufacturer not only provides more buy-back price but also charges more franchise fee to maximize his profit.

(4) Figure 9 demonstrates the manufacturer's expected profit $E\left(\pi_{m H}^{* *}\right)$ and $E\left(\pi_{m L}^{* *}\right)$ decrease firstly and then increase with reward-penalty intensity. Figure10 indicates the expected profit of the retailer $E\left(\pi_{r H H}^{* *}\right)$ increase with reward-penalty intensity while $E\left(\pi_{r L L}^{* *}\right)$ does not change with reward-penalty intensity.

In the context of RPM, the manufacturer's expected profit decreases because the manufacturer faces a penalty when the collection quantity is below the collection quantity target. However, the manufacturer's expected profit increases as the manufacturer gains rewards since the collection quantity surpasses the collection quantity target. Furthermore, the expected profit $E\left(\pi_{r H H}^{* *}\right)$ of the retailer exerting $H$ level of collection effort increases with reward-penalty intensity for the higher buy-back price, however, the expected profit of the retailer exerting $L$ level of collection effort only acquires the conserved profit with the screening contract. Comparing Table 2 with Table 1, we find $E\left(\pi_{m H}^{* *}\right)<E\left(\pi_{m H}^{*}\right), E\left(\pi_{m L}^{* *}\right)<E\left(\pi_{m L}^{*}\right), E\left(\pi_{r H H}^{* *}\right)>E\left(\pi_{r H H}^{*}\right)$, and $E\left(\pi_{r L L}^{* *}\right)=E\left(\pi_{r L L}^{*}\right)$. We can conclude with the comparison that the manufacturer is sensitive to the RPM, whose profit is influenced heavily. If the reward-penalty intensity is high enough, his profit is more than that without RPM. The expected profit of $H$ level retailer with RPM increases, whose profit is more than that without RPM; the expected profit of $L$ level retailer remains acquiring the conserved profit since her collection effort level is lower. 

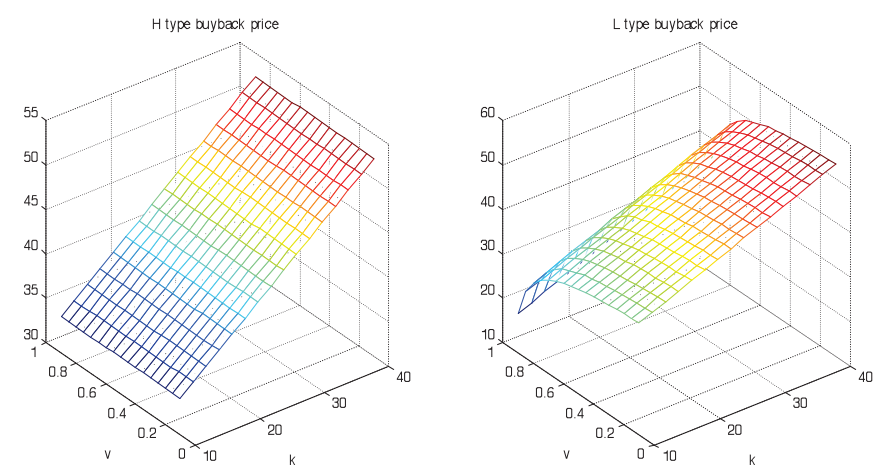

Figure 5. The buyback price $b_{H}^{* *}$ and $b_{L}^{* *}$ vs. $k$ and $v$
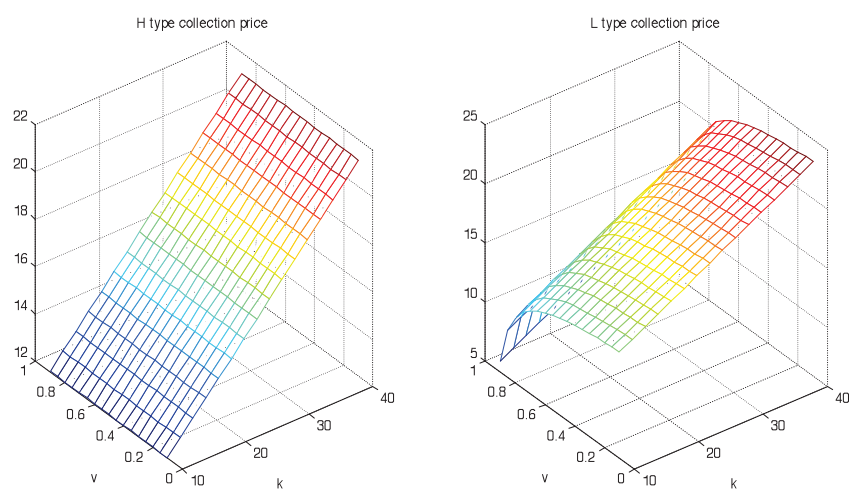

Figure 6. The recovery price $r_{H H}^{* *}$ and $r_{L L}^{* *}$ vs. $k$ and $v$
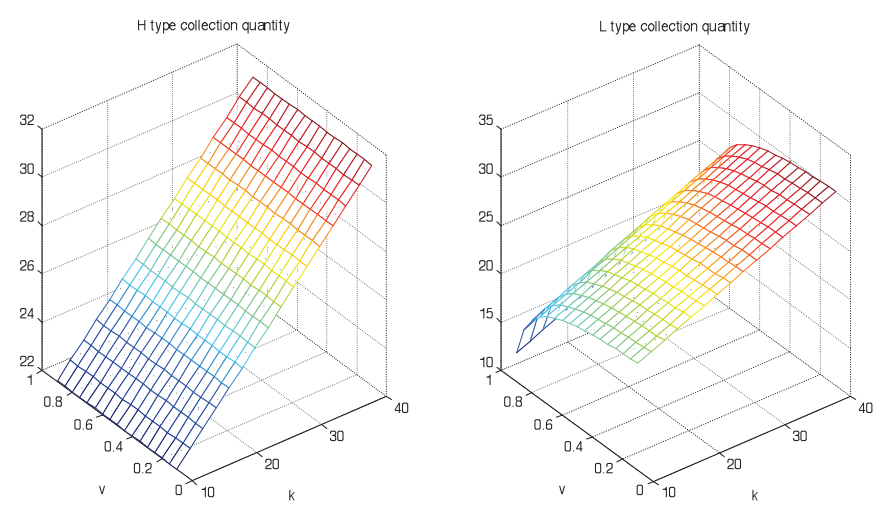

Figure 7. The recovery volume $Q_{H H}^{* *}$ and $Q_{L L}^{* *}$ vs. $k$ and $v$ 

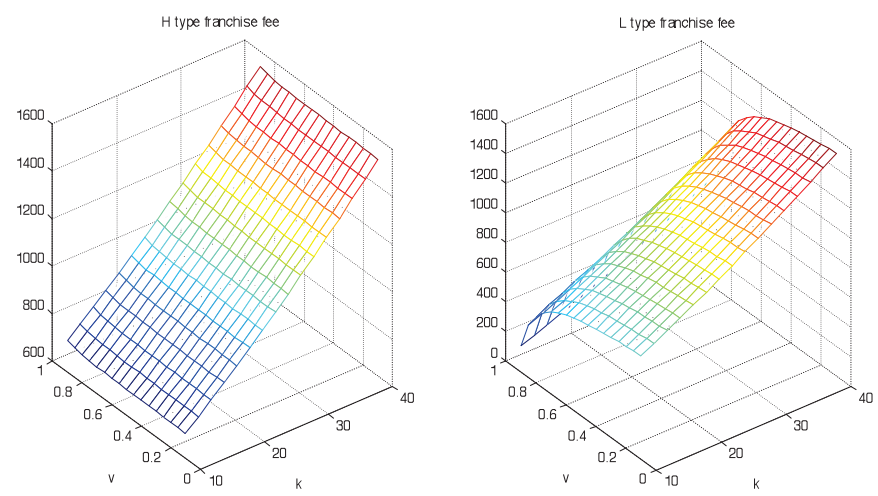

Figure 8. The franchise fee $T_{r H}^{* *}$ and $T_{r L}^{* *}$ vs. $k$ and $v$
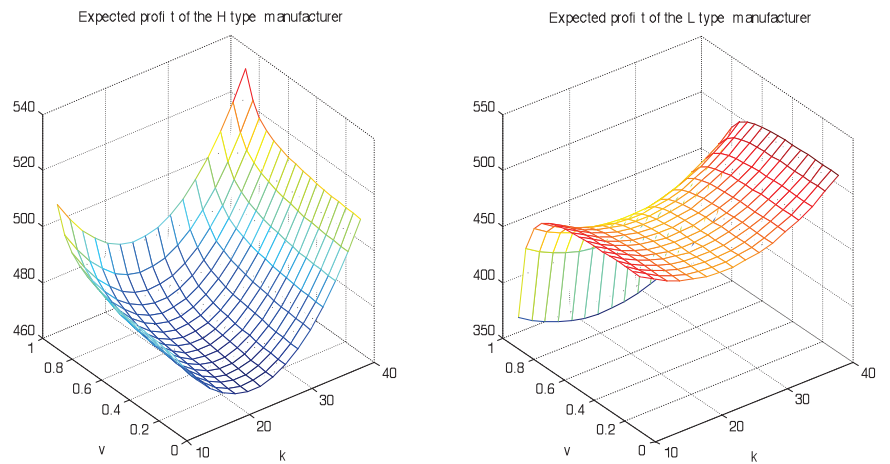

Figure 9. The expected profit of manufacturer $E\left(\pi_{m H}^{* *}\right)$ and $E\left(\pi_{m L}^{* *}\right)$ vs. $k$ and $v$
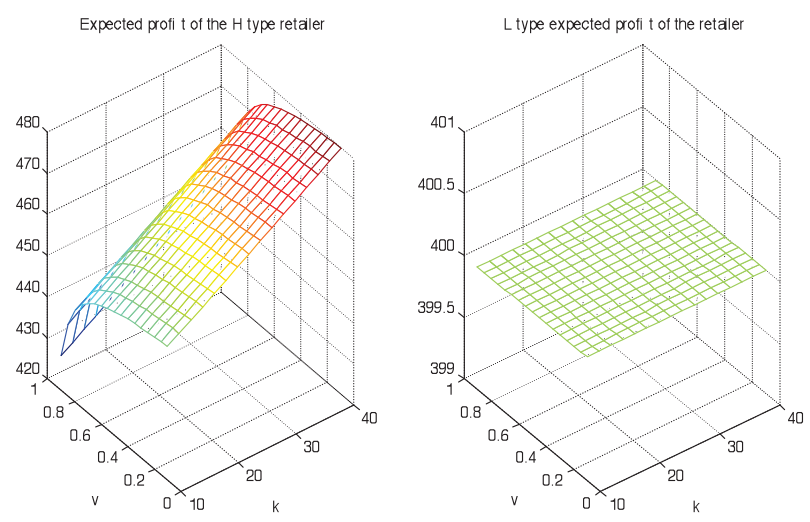

Figure 10. The expected profit of retailer $E\left(\pi_{r H H}^{* *}\right)$ and $E\left(\pi_{r L L}^{* *}\right)$ vs. $k$ and $v$

\section{Conclusions}

This paper explores the information screening contract in the asymmetric information CLSC with or without RPM, where a manufacturer delegates the WEEE collection to a retailer. The retailer can choose to be H-type retailer or L-type retailer while the collection effort level as its own private information unobservable to the manufacturer. We develop the information screening contract in the asymmetric information CLSC with or without RPM. The contract parameters and optimal decision-making results are obtained by solving the models and the main finding are as 
follows:

(1)The information screening contract can enable the manufacturer to obtain the retailer's collection effort level. With the information screening contract, the H-type retailer can only choose the contract $G_{H}$ and the L-type retailer can only choose the contract $G_{L}$. With the information screening contract, the manufacturer would offer lower wholesale price and higher buy-back price for the H-type retailer while charge higher franchise fee to the H-type retailer. Under the contract $G_{H}$, the H-type retailer can collect the waste products and sell products at a lower price.

(2) The RPM can reduce the wholesale price and retail price. Under the RPM, the wholesale price and retail price are lower than those without RPM. The RPM can increase the collection quantity effectively. Under the RPM, the manufacturer would offer higher buy-back price and the retailer would also higher collection price to increase the collection quantity.

(3) The franchise fee in the case with RPM is higher than that without RPM. The buy-back price, collection price, franchise fee and collection quantity increase with reward-penalty intensity while the wholesale price and the retail price decrease with reward-penalty intensity. The expected profit of the H-type retailer increases with reward-penalty intensity, while the L-type retailer's profit remains constant with reward-penalty intensity. The expected profit of the manufacturer decreases before increasing with reward-penalty intensity and with higher reward-penalty intensity, it still will surpass the profit without RPM.

Our paper is among the first efforts to investigate the asymmetric information closed-loop supply chain under the government intervention by developing RPM .There are several possible extensions for the future research. First, in this paper, we assume that the retailer has private information. An important aspect is to look at other CLSC members having private information as was the case with our main focus (retailer). Secondly, we can further perform an analysis by investigating retailer-led CLSC model. Finally, we can explore other objective functions and incorporating decision variables for further research directions.

\section{Acknowledgements}

The authors are grateful to the anonymous referees who provided valuable comments and suggestions, which helped us significantly to improve the quality of the paper. The work was supported by the National Science Foundation of China (No. 71102164, 71271054 and 71571050) and the Fundamental Research Funds for the Central Universities (Project No. 2013W02).

\section{References}

Aksen,D., Aras, N., Karaarslan, A.G., 2009. Design and analysis of government subsidized collection systems for incentive-dependent returns. Int. J. Prod. Econ. 119(2), 308-327.

Aras,N., Güllü, R., Yürülmez, S., 2011. Optimal inventory and pricing policies for remanufacturable leased products. Int. J. Prod. Econ. 133(1), 262-271. 
Atasu, A., Guide Jr., V.D.R., Wassenhove, L.N., 2008. Product reuse economics in closed-loop supply chain research. Prod. \& Oper. Manag. 17 (5), 483-496.

Atasu, A., Oznur, O., Wassenhove, L.N.V., 2013. Stakeholder perspectives on E-waste take-back legislation. Prod. \& Oper. Manag. 22 (2), 382-396.

Atasu, A., Subramanian, R., Extended producer responsibility for E-waste: individual or collective producer responsibility. Prod. \& Oper. Manag. 21(6), 1042-1059.

Atasu,A., Wassenhove, L.N.V., 2010. Environmental legislation on product take-back and collection. In M. Ferguson \& G. Souza (Eds.), Closed-loop supply chains: New CRC Press .23-38.

Atasu, A., Wassenhove, L.N.V., 2012. An operations perspective on product take-back legislation for E-waste: Theory, practice, and research needs. Prod. \& Oper. Manag. 21(3), 407-422.

Atasu, A., Wassenhove, L.N.V., Sarvary, M., 2009. Efficient take-back legislation. Prod. \& Oper. Manag. 18(3), 243-258.

Georgiadis, P., Besiou, M., 2008. Sustainability in electrical and electronic equipment closed-loop supply chains: A System Dynamics approach. J. Clean. Prod. 16(15), 1665-1678.

Giovanni, P.D., Zaccour, G., 2014. A two-period game of a closed-loop supply chain. Eur. J. Oper. Res. 232(1), 22-40.

Giri, B.C., Sharma, S., 2015. Optimal production policy for a closed-loop hybrid system with uncertain demand and return under supply disruption. J. Clean. Prod. 112 (3), 2015-2028.

Govindan, K., Popiuc, M.N., Diabat, A.,2013. Overview of coordination contracts within forward and reverse supply chains. J. Clean. Prod. 47, 319-334.

Govindan, K., Soleimani, H., Kannan, D., 2015. Reverse logistics and closed-loop supply chain: a comprehensive review to explore the future. Eur. J. Oper. Res. 240(1), 603-626.

Hammond, D., Beullens, P., 2007. Closed-loop supply chain network equilibrium under legislation. Eur. J. Oper. Res. 183(2), 895-908.

He, Y.J.,2015. Acquisition pricing and remanufacturing decisions in a closed-loop supply chain. Int. J. Prod. Econ. 163, 48-60.

Huang, M., Song, M., Lee, L.H., Ching, W.K.,2013. Analysis for strategy of closed-loop supply chain with dual recycling channel. Int. J. Prod. Econ. 144(2), 510-520.

Huysman, S., Debaveye, S., Schaubroeck, T., Meester, S.D., Ardente, F., Mathieux, F., Dewulf, J., 2015. The recyclability benefit rate of closed-loop and open-loop systems: A case study on plastic recycling in Flanders. Res. Conser. Rec. 101, 53-60.

Ilgin, M.A., Gupta, S.M., 2010. Environmentally conscious manufacturing and product recovery (ECMPRO): A review of the state of the art. J. Envir. Manag. 91(3), 563-591.

Kaya, O., 2010. Incentive and production decisions for remanufacturing operations. Eur. J. Oper. Res. 201(2), 442-453.

Kenné, J.P., Dejax , P., Gharbi, A.,2009.Production planning of a hybrid manufacturingremanufacturing system under uncertainty within a closed-loop supply chain. Int. J. Prod. Econ. 136(1), 81-93.

Li, X., Li, Y., Govindan, K., 2014. An incentive model for closed-loop supply chain under the EPR law. J. Oper. Res. Soc. 65(1), 88-96.

Ma, W.M., Zhao, Z., Ke, H., 2013. Dual-channel closed-loop supply chain with government consumption-subsidy. Eur. J. Oper. Res. 226(2), 221-227.

Mitra, S., 2007. Revenue management for remanufactured products. Omega. 35 (5), 553-562.

Özkır, V., Başlıgil, H., 2013. Multi-objective optimization of closed-loop supply chains in uncertain environment. J. Clean. Prod .41, 114-125.

Pan, Z., Yu, X., Kai, X.Z., Wei, Y.,2014.Designing contracts for a closed-loop supply chain under information asymmetry. Oper. Res. Lett. 42, 150-155.

Plambeck, E.,Wang, Q.,2009. Effects of e-waste regulation on new product introduction. Manag. 
Sci. 55(3), 333-347.

Rahman, S., Subramanian, N.,2012. Factors for implementing end-of-life computer recycling operations in reverse supply chains. Int. J. Prod. Econ. 140(1), 239-248.

Savaskan, R.C., Bhattacharya, S., Wassenhove, L.N.V., 2004. Closed-Loop supply chain models with product remanufacturing. Manag. Sci. 50(2), 239-252.

Savaskan, R.C, VanWassenhove, L.N.V., 2006. Reverse channel design: the case of competing retailers. Manag. Sci. 52(1), 1-14.

Sharma, V., Garg, S.K., Sharma, P.B., 2016. Identification of major drivers and roadblocks for remanufacturing in India. J. Clean. Prod. 112 (3), 1882-1892.

Sheu, J.B., Chen, Y.J.,2012. Impact of government financial intervention on competition among green supply chains. Int. J. Prod. Econ. 138(1), 201-213.

Souza, G.C.,2013. Closed-Loop Supply Chains: A Critical Review, and Future Research. Deci. Sci. 44(1), 7-38.

Thierry, M., Salomon, M., Nunen, J.V., Wassenhove, L.N.V., 1995. Strategic issues in product recovery management. Calif. Manag. Rev. 37(2), 114-135.

Wang, W.B., Zhang, Y., Zhang, K., Bai, T., Shang, J.,2015. Reward-penalty mechanism for closed-loop supply chains under responsibility-sharing and different power structures. Int. J. Prod. Econ. 170, 178-190.

Webster, S., Mitra, S., 2007. Competitive strategy in remanufacturing and the impact of take-back laws. J. Oper. Manag. 25(6), 1123-1140.

Vlachos, D., Georgiadis, P., Iakovou, E., 2007. A system dynamics model for dynamic capacity planning of remanufacturing in closed-loop supply chains. Comp. \& Oper. Res. 34(2), 367-39.

\section{Appendix}

\section{A1. Proof of Case 1}

\section{Proof.}

Assume $\mathrm{z}_{H}=e_{H}+r_{H H}-\phi+p_{H H}, \mathrm{z}_{L}=e_{L}+r_{L L}-\phi+p_{L L}$, then we have

$$
\begin{aligned}
\mathrm{E}\left(\pi_{m H}\right)= & \int_{0}^{z_{H}}\left(\phi-\mathrm{P}_{H H}+x\right)\left(\omega_{H}-c_{r}\right) f(x) d x \\
& +\int_{z_{H}}^{a}\left(\phi-\mathrm{P}_{H H}+x-e_{H}-r_{H H}\right)\left(\omega_{H}-c_{n}\right) f(x) d x \\
& +\int_{0}^{a}\left(e_{H}+r_{H H}\right)\left(\omega_{H}-c_{r}\right) f(x) d x-b_{H}\left(e_{H}+r_{H H}\right)+\mathrm{T}_{r H} \\
\mathrm{E}\left(\pi_{m L}\right)= & \int_{0}^{z_{L}}\left(\phi-\mathrm{P}_{L L}+x\right)\left(\omega_{L}-c_{r}\right) f(x) d x \\
& +\int_{z L}^{a}\left(\phi-\mathrm{P}_{L L}+x-e_{L}-r_{L L}\right)\left(\omega_{L}-c_{n}\right) f(x) d x \\
& +\int_{0}^{a}\left(e_{L}+r_{L L}\right)\left(\omega_{L}-c_{r}\right) f(x) d x-b_{L}\left(e_{L}+r_{L L}\right)+\mathrm{T}_{r L} \\
\mathrm{E}\left(\pi_{r H H}\right)= & \left(b_{H}-r_{H H}\right)\left(e_{H}+r_{H H}\right)-e_{H}^{2} / 4 \\
& +\left(\mathrm{P}_{H H}-\omega_{H}\right) \int_{0}^{a}\left(\phi-\mathrm{P}_{H H}+x\right) f(x) d x-\mathrm{T}_{r H} \\
\mathrm{E}\left(\pi_{r H L}\right)= & \left(b_{L}-r_{H L}\right)\left(e_{H}+r_{H L}\right)-e_{H}^{2} / 4 \\
& +\left(\mathrm{P}_{H L}-\omega_{L}\right) \int_{0}^{a}\left(\phi-\mathrm{P}_{H L}+x\right) f(x) d x-\mathrm{T}_{r L}
\end{aligned}
$$




$$
\begin{aligned}
& \mathrm{E}\left(\pi_{r L L}\right)=\left(b_{L}-r_{L L}\right)\left(e_{L}+r_{L}\right)-e_{L}^{2} / 4 \\
&+\left(\mathrm{P}_{L L}-\omega_{L}\right) \int_{0}^{a}\left(\phi-\mathrm{P}_{L L}+x\right) f(x) d x-\mathrm{T}_{r L} \\
& \mathrm{E}\left(\pi_{r L H}\right)=\left(b_{H}-r_{L H}\right)\left(e_{L}+r_{L H}\right)-e_{L}^{2} / 4 \\
&+\left(\mathrm{P}_{L H}-\omega_{H}\right) \int_{0}^{a}\left(\phi-\mathrm{P}_{L H}+x\right) f(x) d x-\mathrm{T}_{r H} \\
& \max \mathrm{E}\left(\pi_{m}\right)=v \mathrm{E}\left(\pi_{m H}\right)+(1-v) \mathrm{E}\left(\pi_{m L}\right) \\
&\left(\mathrm{P}^{*}{ }_{H H}, r^{*}{ }_{H H}\right)=\arg \max \mathrm{E}\left(\pi_{r H H}\right) \\
&\left(\mathrm{P}^{*}{ }_{L L}, r^{*}{ }_{L L}\right)=\arg \max \mathrm{E}\left(\pi_{r L L}\right) \\
& \mathrm{E}\left(\pi_{r H H}\right) \geq \mathrm{E}\left(\pi_{r H L}\right) \\
& \mathrm{E}\left(\pi_{r L L}\right) \geq \mathrm{E}\left(\pi_{r L H}\right) \\
& \mathrm{E}\left(\pi_{r H H}\right) \geq \pi_{r}^{0} \\
& \mathrm{E}\left(\pi_{r L L}\right) \geq \pi_{r}^{0}
\end{aligned}
$$

In accordance with Eqs (8) and (9), we define

$$
\left\{\begin{array}{l}
\partial \mathrm{E}\left(\pi_{r H H}\right) / \partial \mathrm{P}_{H H}=0 \\
\partial \mathrm{E}\left(\pi_{r H H}\right) / \partial r_{H H}=0 \\
\partial \mathrm{E}\left(\pi_{r L L}\right) / \partial \mathrm{P}_{L L}=0 \\
\partial \mathrm{E}\left(\pi_{r L L}\right) / \partial r_{L L}=0
\end{array},\right.
$$

thus, we have $\mathrm{P}_{H H}=\frac{\phi+\omega_{H}+a / 2}{2}, r_{H H}=\frac{b_{H}-e_{H}}{2}, \mathrm{P}_{L L}=\frac{\phi+\omega_{L}+a / 2}{2}$ and $r_{L L}=\frac{b_{L}-e_{L}}{2}$

Similarly, based on Eqs (4) and (6), we define

$$
\left\{\begin{array}{l}
\partial \mathrm{E}\left(\pi_{r H L}\right) / \partial \mathrm{P}_{H L}=0 \\
\partial \mathrm{E}\left(\pi_{r H L}\right) / \partial r_{H L}=0 \\
\partial \mathrm{E}\left(\pi_{r L H}\right) / \partial \mathrm{P}_{L H}=0 \\
\partial \mathrm{E}\left(\pi_{r L H}\right) / \partial r_{L H}=0
\end{array}\right.
$$

so we get $\mathrm{P}_{H L}=\frac{\phi+\omega_{H}+a / 2}{2}, r_{H L}=\frac{b_{L}-e_{H}}{2}, \mathrm{P}_{L H}=\frac{\phi+\omega_{L}+a / 2}{2}$ and $r_{L H}=\frac{b_{H}-e_{L}}{2}$.

Taking $\mathrm{P}_{H H}, \mathrm{P}_{L L}, r_{H H}, r_{L L}, \mathrm{P}_{H L}, \mathrm{P}_{L H}, r_{H L}, r_{L H}$, into $\mathrm{E}\left(\pi_{m H}\right), \mathrm{E}\left(\pi_{m L}\right), \mathrm{E}\left(\pi_{r H H}\right)$, $\mathrm{E}\left(\pi_{r L L}\right), \mathrm{E}\left(\pi_{r H L}\right)$ and $\mathrm{E}\left(\pi_{r L H}\right)$,we obtain 


$$
\begin{aligned}
\mathrm{E}\left(\pi_{m H}\right)= & \int_{0}^{z_{H}}\left(\frac{\phi}{2}-\frac{1}{4} a-\frac{\omega_{H}}{2}+x\right)\left(\omega_{H}-c_{r}\right) f(x) d x \\
& +\int_{z_{H}}^{a}\left(\frac{\phi}{2}-\frac{1}{4} a-\frac{\omega_{H}}{2}+x-\frac{e_{H}+b_{H}}{2}\right)\left(\omega_{H}-c_{n}\right) f(x) d x \\
& +\int_{z_{H}}^{a}\left(\frac{e_{H}+b_{H}}{2}\right)\left(\omega_{H}-c_{r}\right) f(x) d x-b_{H}\left(\frac{e_{H}+b_{H}}{2}\right)+\mathrm{T}_{r H} \\
\mathrm{E}\left(\pi_{m L}\right)= & \int_{0}^{z_{L}}\left(\frac{\phi}{2}-\frac{1}{4} a-\frac{\omega_{L}}{2}+x\right)\left(\omega_{L}-c_{r}\right) f(x) d x \\
+ & \int_{z_{L}}^{a}\left(\frac{\phi}{2}-\frac{1}{4} a-\frac{\omega_{L}}{2}+x-\frac{e_{L}+b_{L}}{2}\right)\left(\omega_{L}-c_{n}\right) f(x) d x \\
+ & \int_{z_{L}}^{a}\left(\frac{e_{L}+b_{L}}{2}\right)\left(\omega_{L}-c_{r}\right) f(x) d x-b_{L}\left(\frac{e_{L}+b_{L}}{2}\right)+\mathrm{T}_{r L} \\
\mathrm{E}\left(\pi_{r H H}\right)= & \left(\frac{e_{H}+b_{H}}{2}\right)\left(\frac{e_{H}+b_{H}}{2}\right)-\frac{e_{H}^{2}}{4}+\left(\frac{\phi}{2}+\frac{1}{4} a-\frac{\omega_{H}}{2}\right) \int_{0}^{a}\left(\frac{\phi}{2}-\frac{1}{4} a-\frac{\omega_{H}}{2}+x\right) f(x) d x-\mathrm{T}_{r H} \\
\mathrm{E}\left(\pi_{r L L}\right)= & \left(\frac{e_{L}+b_{L}}{2}\right)\left(\frac{e_{L}+b_{L}}{2}\right)-\frac{e_{L}^{2}}{4}+\left(\frac{\phi}{2}+\frac{1}{4} a-\frac{\omega_{L}}{2}\right) \int_{0}^{a}\left(\frac{\phi}{2}-\frac{1}{4} a-\frac{\omega_{L}}{2}+x\right) f(x) d x-\mathrm{T}_{r L} \\
& +\left(\frac{\phi}{2}+\frac{1}{4} a-\frac{\omega_{H}}{2}\right) \int_{0}^{a}\left(\frac{\phi}{2}-\frac{1}{4} a-\frac{\omega_{H}}{2}+x\right) f(x) d x-\mathrm{T}_{r H} \\
\mathrm{E}\left(\pi_{r L H}\right)= & \left(\frac{e_{L}+b_{H}}{2}\right)\left(\frac{e_{L}+b_{H}}{2}\right)-\frac{e_{H}^{2}}{4} \\
\mathrm{E}\left(\pi_{r H L}\right)= & \left(\frac{e_{H}+b_{L}}{2}\right)\left(\frac{e_{H}+b_{L}}{2}\right)-\frac{e_{H}^{2}}{4} \\
& \left(\frac{\phi}{2}+\frac{1}{4} a-\frac{\omega_{L}}{2}\right) \int_{0}^{a}\left(\frac{\phi}{2}-\frac{1}{4} a-\frac{\omega_{L}}{2}+x\right) f(x) d x-\mathrm{T}_{r L}
\end{aligned}
$$

The original objective function and constraints can be converted as follows:

$$
\begin{aligned}
& \max \mathrm{E}\left(\pi_{m}\right)=v \mathrm{E}\left(\pi_{m H}\right)+(1-v) \mathrm{E}\left(\pi_{m L}\right) \\
& \mathrm{E}\left(\pi_{r H H}\right) \geq \mathrm{E}\left(\pi_{r H L}\right) \\
& \mathrm{E}\left(\pi_{r L L}\right) \geq \mathrm{E}\left(\pi_{r L H}\right) \\
& \mathrm{E}\left(\pi_{r H H}\right) \geq \pi_{r}^{0} \\
& \mathrm{E}\left(\pi_{r L L}\right) \geq \pi_{r}^{0}
\end{aligned}
$$

From Eq (14), we find $\mathrm{E}\left(\pi_{r H H}\right) \geq \mathrm{E}\left(\pi_{r L L}\right)+\frac{b_{L}}{2}\left(e_{H}-e_{L}\right)>\mathrm{E}\left(\pi_{r L L}\right) \geq \pi_{r}^{0}$, thus Eq (17) can be omitted.

Defining $\lambda, \mu, \gamma$ are correspond to the Lagrange multiplier of the constraints, we have 


$$
\begin{aligned}
\frac{\partial L}{\partial b_{H}}= & \frac{1}{2} v\left[\int_{z_{H}}^{a}\left(c_{n}-c_{r}\right) f(x) d x-e_{H}-2 b_{H}\right]+\lambda\left(\frac{e_{H}+b_{H}}{2}\right)-\mu\left(\frac{e_{H}+b_{L}}{2}\right)=0 \\
\frac{\partial L}{\partial b_{L}}= & \frac{1}{2}(1-v)\left[\int_{z_{L}}^{a}\left(c_{n}-c_{r}\right) f(x) d x-e_{L}-2 b_{L}\right]+(\gamma+\mu-\lambda)\left(\frac{e_{L}+b_{L}}{2}\right)=0 \\
\frac{\partial L}{\partial \omega_{H}}= & -\frac{1}{2} v\left[\int_{0}^{z_{H}}\left(\varphi-c_{r}-\frac{1}{2} a+2 x\right) f(x) d x-\int_{z_{H}}^{a}\left(\varphi-c_{n}-\frac{1}{2} a+2 x\right) f(x) d x\right] \\
& -\frac{1}{2}(\lambda+\mu)\left[\left(\varphi-\omega_{H}\right) \int_{0}^{a} f(x) d x+\int_{0}^{a} x f(x) d x\right]=0 \\
\frac{\partial L}{\partial \omega_{L}}= & -\frac{1}{2}(1-v)\left[\int_{0}^{z_{L}}\left(2 \omega_{L}-c_{r}-\varphi+\frac{1}{2} a\right) f(x) d x+\int_{z_{L}}^{a}\left(2 \omega_{L}-c_{n}-\varphi+\frac{1}{2} a\right) f(x) d x+2 \int_{z_{L}}^{a} x f(x) d x\right] \\
& +\frac{1}{2}(\lambda-\mu-\gamma) \int_{0}^{a}\left(\varphi-\omega_{L}+x\right) f(x) d x=0 \\
\frac{\partial L}{\partial \mathrm{T}_{r H}}= & v-\lambda+\mu=0 \\
\frac{\partial L}{\partial \mathrm{T}_{r L}} & =1-v+\lambda-\mu-\gamma=0
\end{aligned}
$$

From $\frac{\partial L}{\partial \mathrm{T}_{r H}}=0 \boldsymbol{\boldsymbol { f }} \frac{\partial L}{\partial \mathrm{T}_{r L}}=0$, we get $\lambda=\boldsymbol{v}+\mu \geq 0 \boldsymbol{\in} \gamma=\mathrm{t} \geq 0$ and have $\mu=0$ further.

(Disproof: we assume $\mu>0$, the corresponding constraint (16) must get equal interms of K-T. Similarly, $\lambda=v+\mu \geq 0$ indicates the constraint (15) is proper. Combining constraints (15) and (16), we have $\mathrm{E}\left(\pi_{r H H}\right)=\mathrm{E}\left(\pi_{r H L}\right) £ \mathrm{E}\left(\pi_{r L L}\right)=\mathrm{E}\left(\pi_{r L H}\right)$ and know that assumption $\mu>0$ is not reasonable, thus, we get $\mu=0$ )

When $\gamma>0, \mathrm{E}\left(\pi_{r L L}\right)=\pi_{r}^{0}$. When $\lambda>0, \mathrm{E}\left(\pi_{r H H}\right)=\mathrm{E}\left(\pi_{r H L}\right)$, so

$$
\mathrm{E}\left(\pi_{r H H}\right)=\pi_{\mathrm{r}}^{0}+\frac{\mathrm{b}_{L}}{2}\left(e_{H}-e_{L}\right)
$$

From $\frac{\partial L}{\partial \omega_{H}}=0$, we have $\omega_{H}^{*}=\frac{4 \Delta\left(\phi-\mathrm{e}_{H}\right)-3 \Delta^{2}+(\Delta+2 \mathrm{a})\left(c_{r}+3 c_{n}\right)}{8(\Delta+\mathrm{a})}$;

From $\frac{\partial L}{\partial \omega_{L}}=0$, we get

$$
\omega_{L}^{*}=\frac{4 \Delta\left(\phi-\mathrm{e}_{H}\right)-3 \Delta^{2}+(\Delta+2 \mathrm{a})\left(c_{r}+3 c_{n}\right)}{8(\Delta+\mathrm{a})}-\frac{\Delta\left(\mathrm{e}_{L}-v e_{H}\right)}{2(1-v)(\Delta+\mathrm{a})} ;
$$

From $\frac{\partial L}{\partial b_{H}}=0$, we have $b_{H}^{*}=\frac{\Delta\left(\phi-e_{H}-\omega_{H}^{*}+3 a / 2\right)}{\Delta+2 a} ;$ 
From $\frac{\partial L}{\partial b_{L}}=0$, we have $b_{L}^{*}=\frac{\Delta\left(\phi-\omega_{L}^{*}+3 a / 2\right)}{\Delta+2 a}-\frac{[\Delta(1-v)-2 a v] e_{L}+2 a v e_{H}}{(1-v)(\Delta+2 a)}$

We already know $\omega_{H}^{*}, \mathrm{~b}_{H}^{*}, \mathrm{E}\left(\pi_{r H H}\right)=\pi_{\mathrm{r}}^{0}+\frac{\mathrm{b}_{L}}{2}\left(e_{H}-e_{L}\right), \omega_{L}^{*}, \mathrm{~b}_{L}^{*}$, thus, we get

$$
\mathrm{T}_{r H}^{*}=\frac{\left(\mathrm{b}_{H}^{*}+e_{H}\right)^{2}+\left(\phi-\omega_{H}^{*}+a / 2\right)^{2}-\left(\mathrm{b}_{L}^{*}+e_{H}\right)^{2}-\left(\phi-\omega_{L}^{*}+a / 2\right)^{2}}{4}+\mathrm{T}_{r L}^{*}
$$

Similarly, we have $\omega_{L}^{*}, \mathrm{~b}_{L}^{*} £ \mathrm{E}\left(\pi_{r L L}\right)=\pi_{r}^{0}, \mathrm{so}_{\mathrm{rL}}^{*}=\frac{\left(\mathrm{b}_{L}^{*}+e_{L}\right)^{2}-e_{L}^{2}+\left(\phi-\omega_{L}^{*}+a / 2\right)^{2}}{4}-\pi_{r}^{0}$

For further, we obtain

$$
\mathrm{P}_{H H}^{*}=\frac{\phi+\omega_{H}^{*}+a / 2}{2}, \mathrm{P}_{L L}^{*}=\frac{\phi+\omega_{L}^{*}+a / 2}{2}, r_{H H}^{*}=\frac{b_{H}^{*}-e_{H}}{2} \text { and } r_{L L}^{*}=\frac{b_{L}^{*}-e_{L}}{2} .
$$

\section{A2. Proof of Case 2}

\section{Proof.}

We assume $\mathrm{z}_{H}=e_{H}+r_{H H}-\phi+\mathrm{P}_{H H}, \mathrm{z}_{L}=e_{L}+r_{L L}-\phi+\mathrm{P}_{L L}$, then

$$
\begin{aligned}
& \mathrm{E}\left(\pi_{m H}\right)=\int_{0}^{z_{H}}\left(\phi-\mathrm{P}_{H H}+x\right)\left(\omega_{H}-c_{r}\right) f(x) d x+\int_{z_{H}}^{a}\left(\phi-\mathrm{P}_{H H}+x-e_{H}-r_{H H}\right)\left(\omega_{H}-c_{n}\right) f(x) d x \\
& +\int_{0}^{a}\left(e_{H}+r_{H H}\right)\left(\omega_{H}-c_{r}\right) f(x) d x-b_{H}\left(e_{H}+r_{H H}\right)+\mathrm{T}_{r H}+k\left(Q_{H H}-Q_{0}\right) \\
& \mathrm{E}\left(\pi_{m L}\right)=\int_{0}^{z_{L}}\left(\phi-\mathrm{P}_{L L}+x\right)\left(\omega_{L}-c_{r}\right) f(x) d x+\int_{z L}^{a}\left(\phi-\mathrm{P}_{L L}+x-e_{L}-r_{L L}\right)\left(\omega_{L}-c_{n}\right) f(x) d x \\
& +\int_{0}^{a}\left(e_{L}+r_{L L}\right)\left(\omega_{L}-c_{r}\right) f(x) d x-b_{L}\left(e_{L}+r_{L L}\right)+\mathrm{T}_{r L}+k\left(Q_{L L}-Q_{0}\right) \\
& \mathrm{E}\left(\pi_{r H H}\right)=\left(b_{H}-r_{H H}\right)\left(e_{H}+r_{H H}\right)-e_{H}^{2} / 4+\left(\mathrm{P}_{H H}-\omega_{H}\right) \int_{0}^{a}\left(\phi-\mathrm{P}_{H H}+x\right) f(x) d x-\mathrm{T}_{r H} \\
& \mathrm{E}\left(\pi_{r H L}\right)=\left(b_{L}-r_{H L}\right)\left(e_{H}+r_{H L}\right)-e_{H}^{2} / 4+\left(\mathrm{P}_{H L}-\omega_{L}\right) \int_{0}^{a}\left(\phi-\mathrm{P}_{H L}+x\right) f(x) d x-\mathrm{T}_{r L} \\
& \mathrm{E}\left(\pi_{r L L}\right)=\left(b_{L}-r_{L L}\right)\left(e_{L}+r_{L}\right)-e_{L}^{2} / 4+\left(\mathrm{P}_{L}-\omega_{L}\right) \int_{0}^{a}\left(\phi-\mathrm{P}_{L L}+x\right) f(x) d x-\mathrm{T}_{r L} \\
& \mathrm{E}\left(\pi_{r L H}\right)=\left(b_{H}-r_{L H}\right)\left(e_{L}+r_{L H}\right)-e_{L}^{2} / 4+\left(\mathrm{P}_{L H}-\omega_{H}\right) \int_{0}^{a}\left(\phi-\mathrm{P}_{L H}+x\right) f(x) d x-\mathrm{T}_{r H} \\
& \max \mathrm{E}\left(\pi_{m}\right)=v \mathrm{E}\left(\pi_{m H}\right)+(1-v) \mathrm{E}\left(\pi_{m L}\right) \\
& \left(\mathrm{P}_{H H}^{* *}, r_{H H}^{* *}\right)=\arg \max \mathrm{E}\left(\pi_{r H H}\right) \\
& \left(\mathrm{P}_{L L}^{* *}, r_{L L}^{* *}\right)=\arg \max \mathrm{E}\left(\pi_{r L L}\right) \\
& \mathrm{E}\left(\pi_{r H H}\right) \geq \mathrm{E}\left(\pi_{r H L}\right) \\
& \mathrm{E}\left(\pi_{r L L}\right) \geq \mathrm{E}\left(\pi_{r L H}\right) \\
& \mathrm{E}\left(\pi_{r H H}\right) \geq \pi_{r}^{0}
\end{aligned}
$$


$\mathrm{E}\left(\pi_{r L L}\right) \geq \pi_{r}^{0}$

For Eqs (26) and (27), let $\partial \mathrm{E}\left(\pi_{r H H}\right) / \partial \mathrm{P}_{H H}=0, \partial \mathrm{E}\left(\pi_{r H H}\right) / \partial \mathrm{r}_{H H}=0$, $\partial \mathrm{E}\left(\pi_{r L L}\right) / \partial \mathrm{P}_{L L}=0$ and $\partial \mathrm{E}\left(\pi_{r L L}\right) / \partial r_{L L}=0$, so we have

$$
\mathrm{P}_{H H}=\frac{\phi+\omega_{H}+a / 2}{2}, r_{H H}=\frac{b_{H}-e_{H}}{2}, \mathrm{P}_{L L}=\frac{\phi+\omega_{L}+a / 2}{2}, r_{L L}=\frac{b_{L}-e_{L}}{2} .
$$

For Eqs 22) and (24), let $\partial \mathrm{E}\left(\pi_{r H L}\right) / \partial \mathrm{P}_{H L}=0, \partial \mathrm{E}\left(\pi_{r H L}\right) / \partial r_{H L}=0$, $\partial \mathrm{E}\left(\pi_{r L H}\right) / \partial \mathrm{P}_{L H}=0$ and $\partial \mathrm{E}\left(\pi_{r L H}\right) / \partial r_{L H}=0$, we get

$$
\mathrm{P}_{H L}=\frac{\phi+\omega_{H}+a / 2}{2}, r_{H L}=\frac{b_{L}-e_{H}}{2}, \mathrm{P}_{L H}=\frac{\phi+\omega_{L}+a / 2}{2}, r_{L H}=\frac{b_{H}-e_{L}}{2} .
$$

Substituting $\mathrm{P}_{H H}, \mathrm{P}_{L L}, r_{H H}, r_{L L}, \mathrm{P}_{H L}, \mathrm{P}_{L H}, r_{H L}$ and $r_{L H}$ into $\mathrm{E}\left(\pi_{m H}\right), \mathrm{E}\left(\pi_{m L}\right), \mathrm{E}\left(\pi_{r H H}\right)$, $\mathrm{E}\left(\pi_{r L L}\right), \mathrm{E}\left(\pi_{r H L}\right)$ and $\mathrm{E}\left(\pi_{r L H}\right)$, we have

$$
\begin{aligned}
& E\left(\pi_{m H}\right)= \int_{0}^{z_{H}}\left(\frac{\varphi}{2}-\frac{1}{4} a-\frac{\omega_{H}}{2}+x\right)\left(\omega_{H}-c_{r}\right) f(x) d x+\int_{z_{H}}^{a}\left(\frac{\varphi}{2}-\frac{1}{4} a-\frac{\omega_{H}}{2}+x\right)\left(\omega_{H}-c_{n}\right) f(x) d x \\
&-\int_{z_{H}}^{a}\left(\frac{e_{H}+b_{H}}{2}\right)\left(c_{n}-c_{r}\right) f(x) d x-b_{H}\left(\frac{e_{H}+b_{H}}{2}\right)+T_{r H}+k\left(\frac{e_{H}+b_{H}}{2}-Q_{0}\right) \\
& E\left(\pi_{m L}\right)=\int_{0}^{z_{L}}\left(\frac{\varphi}{2}-\frac{1}{4} a-\frac{\omega_{L}}{2}+x\right)\left(\omega_{L}-c_{r}\right) f(x) d x+\int_{z_{L}}^{a}\left(\frac{\varphi}{2}-\frac{1}{4} a-\frac{\omega_{L}}{2}+x\right)\left(\omega_{L}-c_{n}\right) f(x) d x \\
&-\int_{z_{L}}^{a}\left(\frac{e_{L}+b_{L}}{2}\right)\left(c_{n}-c_{r}\right) f(x) d x-b_{L}\left(\frac{e_{L}+b_{L}}{2}\right)+T_{r L}+k\left(\frac{e_{L}+b_{L}}{2}-Q_{0}\right) \\
& \mathrm{E}\left(\pi_{r H H}\right)=\left(\frac{e_{H}+b_{H}}{2}\right)\left(\frac{e_{H}+b_{H}}{2}\right)-\frac{e_{H}^{2}}{4}+\left(\frac{\phi}{2}+\frac{1}{4} a-\frac{\omega_{H}}{2}\right) \int_{0}^{a}\left(\frac{\phi}{2}-\frac{1}{4} a-\frac{\omega_{H}}{2}+x\right) f(x) d x-\mathrm{T}_{r H} \\
& \mathrm{E}\left(\pi_{r L L}\right)=\left(\frac{e_{L}+b_{L}}{2}\right)\left(\frac{e_{L}+b_{L}}{2}\right)-\frac{e_{L}^{2}}{4}+\left(\frac{\phi}{2}+\frac{1}{4} a-\frac{\omega_{L}}{2}\right) \int_{0}^{a}\left(\frac{\phi}{2}-\frac{1}{4} a-\frac{\omega_{L}}{2}+x\right) f(x) d x-\mathrm{T}_{r L} \\
& \mathrm{E}\left(\pi_{r H L}\right)=\left(\frac{e_{H}+b_{L}}{2}\right)\left(\frac{e_{H}+b_{L}}{2}\right)-\frac{e_{H}^{2}}{4}+\left(\frac{\phi}{2}+\frac{1}{4} a-\frac{\omega_{L}}{2}\right) \int_{0}^{a}\left(\frac{\phi}{2}-\frac{1}{4} a-\frac{\omega_{L}}{2}+x\right) f(x) d x-\mathrm{T}_{r L} \\
& \mathrm{E}\left(\pi_{r L H}\right)=\left(\frac{e_{L}+b_{H}}{2}\right)\left(\frac{e_{L}+b_{H}}{2}\right)-\frac{e_{H}^{2}}{4}+\left(\frac{\phi}{2}+\frac{1}{4} a-\frac{\omega_{H}}{2}\right) \int_{0}^{a}\left(\frac{\phi}{2}-\frac{1}{4} a-\frac{\omega_{H}}{2}+x\right) f(x) d x-\mathrm{T}_{r H}
\end{aligned}
$$

The original objective function and constraints can be converted as follows:

$$
\begin{gathered}
\max \mathrm{E}\left(\pi_{m}\right)=v \mathrm{E}\left(\pi_{m H}\right)+(1-v) \mathrm{E}\left(\pi_{m L}\right) \\
\mathrm{E}\left(\pi_{r H H}\right) \geq \mathrm{E}\left(\pi_{r H L}\right) \\
\mathrm{E}\left(\pi_{r L L}\right) \geq \mathrm{E}\left(\pi_{r L H}\right) \\
\mathrm{E}\left(\pi_{r H H}\right) \geq \pi_{r}^{0} \\
\mathrm{E}\left(\pi_{r L L}\right) \geq \pi_{r}^{0}
\end{gathered}
$$

From Eqs (33) and (36), we have 


$$
\mathrm{E}\left(\pi_{r H H}\right) \geq \mathrm{E}\left(\pi_{r L L}\right)+\frac{b_{L}}{2}\left(e_{H}-e_{L}\right)>\mathrm{E}\left(\pi_{r L L}\right) \geq \pi_{r}^{0},
$$

which can lead to ignoring Eq (35).

Defining $\lambda, \mu, \gamma$ are correspond to the Lagrange multiplier of the constraints, we have

$$
\begin{aligned}
\frac{\partial L}{\partial b_{H}}= & \frac{1}{2} v\left[\int_{z_{H}}^{a}\left(c_{n}-c_{r}\right) f(x) d x-e_{H}-2 b_{H}\right]+\lambda\left(\frac{e_{H}+b_{H}}{2}\right)-\mu\left(\frac{e_{H}+b_{L}}{2}\right)+\frac{k}{2}=0 \\
\frac{\partial L}{\partial b_{L}}= & \frac{1}{2}(1-v)\left[\int_{z_{L}}^{a}\left(c_{n}-c_{r}\right) f(x) d x-e_{L}-2 b_{L}\right]+(\mu+\gamma-\lambda)\left(\frac{e_{L}+b_{L}}{2}\right)+\frac{k}{2}=0 \\
\frac{\partial L}{\partial \omega_{H}}= & \frac{1}{2} v\left[\int_{0}^{z_{H}}\left(\varphi-\frac{1}{2} a-2 \omega+2 x+c_{r}\right) f(x) d x+\int_{z_{H}}^{a}\left(\varphi-\frac{1}{2} a-2 \omega+2 x+c_{n}\right) f(x) d x\right] \\
& +\frac{1}{2}(\mu-\lambda) \int_{0}^{a}\left(\varphi-\omega_{H}+x\right) f(x) d x=0 \\
\frac{\partial L}{\partial \omega_{L}}= & \frac{1}{2}(1-v)\left[\int_{0}^{z_{L}}\left(\varphi-\frac{1}{2} a-2 \omega_{H}+2 x+c_{r}\right) f(x) d x+\int_{z_{L}}^{a}\left(\varphi-\frac{1}{2} a-2 \omega_{H}+2 x+c_{n}\right) f(x) d x\right] \\
\quad+\frac{1}{2}(\lambda-\mu-\gamma) \int_{0}^{a}\left(\varphi-\omega_{L}+x\right) f(x) d x=0 & \\
\frac{\partial L}{\partial \mathrm{T}_{r H}}= & v-\lambda+\mu=0 \\
\frac{\partial L}{\partial \mathrm{T}_{r L}} & =1-v+\lambda-\mu-\gamma=0
\end{aligned}
$$

From $\frac{\partial L}{\partial \mathrm{T}_{r H}}=0$ and $\frac{\partial L}{\partial \mathrm{T}_{r L}}=0$, we have $\lambda=\boldsymbol{v}+\boldsymbol{\mu} \geq 0 \boldsymbol{\in} \quad \gamma=\mathbf{p} \geq 0$

For further, we have $\mu=0$ (Disproof: assume $\mu>0$, the corresponding constraint (34) must get equal in terms of K-T. Similarly, from $\lambda=v+\mu \geq 0$, the constraint (2) gets equal. Combining constraints (33) and (34), we have $\mathrm{E}\left(\pi_{r H H}\right)=\mathrm{E}\left(\pi_{r H L}\right) \mathbf{E} \mathrm{E}\left(\pi_{r L L}\right)=\mathrm{E}\left(\pi_{r L H}\right)$, the assumption that $\mu>0$ is not proper, thus, we have $\mu=0$ )

When $\gamma>0, \mathrm{E}\left(\pi_{r L L}\right)=\pi_{r}^{0} ;$ When $\lambda>0, \mathrm{E}\left(\pi_{r H H}\right)=\pi_{\mathrm{r}}^{0}+\frac{\mathrm{b}_{L}}{2}\left(e_{H}-e_{L}\right)$.

From $\frac{\partial L}{\partial b_{H}}=0$, we have $b_{H}=\frac{\Delta\left(\phi-e_{H}-\omega_{H}+3 a / 2\right)+2 a k}{\Delta+2 a}$;

From $\frac{\partial L}{\partial b_{L}}=0$, we get $b_{L}=\frac{\Delta\left(\phi-\omega_{L}+3 a / 2\right)+2 a k}{\Delta+2 a}-\frac{[\Delta(1-v)-2 a v] e_{L}+2 a v e_{H}}{(1-v)(\Delta+2 a)}$

From $b_{H}, \frac{\partial L}{\partial \omega_{H}}=0$, we obtain

$$
w_{H}^{* *}=\frac{4 \Delta\left(\phi-\mathrm{e}_{H}-k\right)-3 \Delta^{2}+(\Delta+2 \mathrm{a})\left(c_{r}+3 c_{n}\right)}{8(\Delta+\mathrm{a})}
$$


From $b_{L}, \frac{\partial L}{\partial \omega_{L}}=0$, we have

$$
w_{L}^{* *}=\frac{4 \Delta(\phi-k)-3 \Delta^{2}+(\Delta+2 \mathrm{a})\left(c_{r}+3 c_{n}\right)}{8(\Delta+\mathrm{a})}-\frac{\Delta\left(\mathrm{e}_{L}-v e_{H}\right)}{2(1-v)(\Delta+\mathrm{a})}
$$

Combining above results, we get

$$
b_{L}^{* *}=\frac{\Delta\left(\phi-\omega_{L}^{* *}+3 a / 2\right)+2 a k}{\Delta+2 a}-\frac{[\Delta(1-v)-2 a v] e_{L}+2 a v e_{H}}{(1-v)(\Delta+2 a)}
$$

From $\omega_{L}^{* *}, \mathrm{~b}_{L}^{* *} \mathbf{f} \mathrm{E}\left(\pi_{r L L}\right)=\pi_{r}^{0}$, we have $\mathrm{T}_{\mathrm{rL}}^{* *}=\frac{\left(\mathrm{b}_{L}^{* *}+e_{L}\right)^{2}-e_{L}^{2}+\left(\phi-\omega_{L}^{* *}+a / 2\right)^{2}}{4}-\pi_{r}^{0}$.

From $\omega_{H}^{* *}, \mathrm{~b}_{H}^{* *}, \mathrm{E}\left(\pi_{r H H}\right)=\pi_{\mathrm{r}}^{0}+\frac{\mathrm{b}_{L}}{2}\left(e_{H}-e_{L}\right), \omega_{L}^{* *}, \mathrm{~b}_{L}^{* *}, \mathrm{~T}_{r L}^{* *}$, we obtain

$$
\mathrm{T}_{r H}^{* *}=\frac{\left(\mathrm{b}_{H}^{* *}+e_{H}\right)^{2}+\left(\phi-\omega_{H}^{* *}+a / 2\right)^{2}-\left(\mathrm{b}_{L}^{* *}+e_{H}\right)^{2}-\left(\phi-\omega_{L}^{* *}+a / 2\right)^{2}}{4}+\mathrm{T}_{r L}^{* *}
$$

Furthermore, we get $p_{H H}^{* *}=\frac{\phi+\omega_{H}^{* *}+a / 2}{2}, p_{L L}^{* *}=\frac{\phi+\omega_{L}^{* *}+a / 2}{2}, r_{H H}^{* *}=\frac{b_{H}^{* *}-e_{H}}{2}$ and $r_{L L}^{* *}=\frac{b_{L}^{* *}-e_{L}}{2}$. 